\title{
Convection-Diffusion Model for the Prediction of Anthropogenically-Initiated Wildfire Ignition
}

\author{
Ravi Sadasivuni $\cdot$ Shanti Bhushan $\cdot$ William H. Cooke
}

Published online: 11 December 2014

(C) The Author(s) 2014. This article is published with open access at Springerlink.com

\begin{abstract}
A spatial interaction model to predict anthropogenically-initiated accidental and incendiary wildfire ignition probability is developed using fluid flow analogies for human movement patterns. Urban areas with large populations are identified as the sites of global influencing factors, and are modeled as the gravity term. The transportation corridors are identified as local influencing factors, and are modeled using fluid flow analogy as diffusion and convection terms. The model is implemented in ArcGIS, and applied for the prediction of wildfire hazard distribution in southeastern Mississippi. The model shows $87 \%$ correlation with historic data in the winter season, whereas the previously developed gravity model shows only $75 \%$ correlation. The normalized error for convection-diffusion model predictions is about $5 \%$ in the winter season, whereas the gravity model shows an error of $7 \%$. The proposed model is robust as it couples a multi-criteria behavioral pattern within a single dynamic equation to enhance predictive capability. At the same time, the proposed model is more costly than the gravity model as it requires evaluation of distance from intermodal transportation corridors, transportation corridor density, and traffic volume maps. Nonetheless, the model is developed in a modular fashion, such that either global or local terms can be neglected if required.
\end{abstract}

\footnotetext{
R. Sadasivuni · W. H. Cooke ( $₫)$

Department of Geosciences, Mississippi State University,

Starkville, MS 39759, USA

e-mail:whc5@geosci.msstate.edu

S. Bhushan

Center for Advance Vehicular Systems, Mississippi State

University, Starkville, MS 39759, USA
}

Keywords Anthropogenic-fire - Convection-diffusion model · Fire ignition potential · Mississippi · Wildfire hazard

\section{Introduction}

Wildfires pose serious economic and environmental hazard over much of the United States, and have significant impact on the availability of cultural resources and ecosystem functions primarily due to land cover changes (Eccleston 2011). Although the impact of wildfires on ecosystem/ cultural resources is more or less understood, our understanding of the complex set of biophysical and social factors that initiate such events is less well developed. Development of better understanding of such factors, including better knowledge of the natural ecological role of fires in wilderness, is critical for wildfire management and prevention (USDA and USDI 1998). From a very broad perspective, the occurrence of wildfires depends on the availability of fuels and the presence of an ignition source (Pew et al. 2001; Zhai et al. 2003; Brewer and Rogers 2006; Cooke et al. 2007). Fuels usually derive from the vegetation loads including both horizontal and vertical vegetation structure. The spatial distribution of fuel loads depends on vegetative characteristics, whereas the temporal variations are governed by meteorological conditions, including drought events (Grala and Cooke 2010).

Wildfires are ignited either by natural causes or anthropogenically-initiated events. Pyne et al. (1996) concluded that the historic ranges of variability suggest that the distribution of wildfires across the landscape is shifting, and that the majority of wildfires nowadays are burning closer to developed areas of the wildland-urban interface. Human-initiated fires constitute more than two-thirds of all 
wildfires in the United States, and the numbers are even larger for the southern U.S. (Sadasivuni 2013). There are three main categories of antropogenically-initiated wildfire ignition sources: accidental, incendiary, and prescribed (Zhai et al. 2003). Accidental fires are unintentionally started, such as by children, camp fires, smoking, hunting, vehicles, and railroads. Incendiary fire is a broad category that takes into account wildfires started through negligence or arson fires set with malicious intent (Kraskey 1985; Kuhlken 1999). Prescribed fires are set in a controlled environment to compensate for the lack of natural fire and burn off accumulated fuel to mitigate or better manage future wildfire events (Parsons 2000). Overall, studies have shown a strong influence of humans on the spatial pattern of wildfire, either as the ignition source at shorter distances to human infrastructure (Pyne et al. 1996; Cardille et al. 2001; Petrakis et al. 2005; Stephens 2005; Yang et al. 2007; Grala and Cooke 2010), or by management efforts to suppress wilderness fires (Miller 2003).

\subsection{Review of Wildfire Hazard Prediction and Spatial-Interaction Models}

Most commonly used wildfire hazard description models are developed using statistical techniques, such as regression or weights-of-evidence methods, to identify the correlation between the historical observational data and geographical locations, landscape, meteorological conditions, vegetation components, or human influence. Key correlation studies are summarized below in chronological order.

Burgan et al. (1998) developed a fuel model map for the entire United States to generate a fire danger rating system for the country. The fuel map was generated by mapping the land cover classes and ecoregions derived from extensive ground and satellite data. The model was used to study the correlation between the fire potential index and fire occurrence in California and Nevada.

Models were developed and validated by Vasconcelos et al. (2001) to predict wildfire ignition probability by constructing regression and neural network correlations between ignition location/cause and geographical and environmental variables. The model was applied to prediction of wildfires in central Portugal. It was concluded that both the models reveal acceptable levels of predictive ability, but the neural networks approach provided better accuracy and robustness.

The Blue Mountain region of Oregon and Washington states was the setting in which Heyerdahl et al. (2001) examined the controls affecting spatial variation in fire regimes, using multi-century historical data about fire frequency, size, season, and severity. Their study demonstrated that prior to the 1900 s both the regional climate and local topography played an important role and acted simultaneously to influence the fire regimes in the region. However, in the twentieth century the fire regimes were dramatically affected by additional controls such as livestock grazing and wildfire suppression.

Haight et al. (2004) identified areas of the wildlandurban interface that are prone to severe wildfire in northern Michigan. For this purpose, they compared the spatial database of historic (pre-1900) wildfire regimes and current fuels with housing data from the 2000 U.S. Census. The study concluded that $25 \%$ of the wildland-urban interface has relatively high fire risk, and $88 \%$ of that area has low housing density.

A database of lightning- and human-caused wildfires was assembled by Dickson et al. (2006) for the 15-year period between 1986 and 2000 in the forested region of northern Arizona. They used a weights-of-evidence approach to model and map the probability of wildfire occurrence based on fire type. Analysis showed that lightning fires were more frequent and extensive than those caused by humans, although human-caused wildfires burned large areas during the period. For all wildfires, probability of occurrence was greatest in areas of high topographic roughness and lower road-density.

Cooke et al. (2007) and Gilreath (2006) have analyzed wildfire occurrence as it relates to vegetation, precipitation, and road-density (total length of the road polyline feature per unit area) data in Mississippi for the 15-year period between 1991 and 2005 to identify the variables that most closely describe wildfire distribution. Gilreath (2006) concluded that there was a good spatial correlation between the wildfire events and dynamic meteorological conditions (water budget). Road density, including both designated highways and county roads, was found to be a good indicator of wildfire frequency; in particular, areas of moderate road density correlate with significantly higher hazard. Grala and Cooke (2010) found that $60-70 \%$ of wildfires occur within a $1 \mathrm{~km}$ buffer $^{1}$ zone along the designated highways.

Syphard et al. (2007) examined the human influence on wildfires in California. For this purpose correlation of housing density, distance from wildland-urban interface (WUI), population density, road-density, vegetation type, and ecoregion with contemporary (2000) and historic (1960-2000) wildfire data were studied. The study showed strong correlation between population density, intermix WUI, and distance to WUI and wildfire frequency, suggesting that the spatial pattern of development may be an important variable to consider when estimating wildfire risk.

\footnotetext{
${ }^{1}$ Buffer zone refers to an area within a specific distance on either side of a feature, such as road, railroad, and so on.
} 
In Spain, Romero-Calcerrada et al. (2008) used a weights-of-evidence method to examine the factors influencing wildfires southwest of Madrid for two different wildfire seasons. The results showed that the spatial patterns of wildfire ignition are strongly associated with human access to the natural landscape, with proximity to urban areas and roads as the most important factors. Further, wildfire ignition distributions in these Mediterranean regions were found to be similar to those in California, where the WUI is large and recreation in forested areas is high. They concluded that their weights-of-evidence model was a useful tool for wildfire risk prediction.

Catry et al. (2009) analyzed wildfires in Portugal during a 5-year period. They used logistic regression models to predict the likelihood of ignition occurrence. Using a set of potentially explanatory variables, their study identified population density, human accessibility, land cover, and elevation as the important determinants of the spatial distribution of wildfire ignitions. The derived regression model performed well in predicting spatial patterns of wildfire ignitions at the national level with good accuracy.

The logistic regression models used by Narayanaraj and Wimberly (2012) examined the correlation between lightning- and human-caused wildfire ignitions, as well as other anthropogenic and biophysical factors, causing impacts on forest road corridors in the eastern Cascade Mountains of Washington State. Their study showed that human-caused ignitions were concentrated close to roads, in high roaddensity areas, and near the WUI. In contrast, lightningcaused ignitions were concentrated in low road-density areas, away from WUI, and in low population density areas. They concluded that roads and their edge effect areas should be acknowledged as a unique type of landscape effect in fire research and management.

Recently, Faivre et al. (2014) investigated the relative importance of physical, climatic, and human factors in regulating ignition probability across Southern California's National Forests. For this purpose a 30-year record of wildfire data was analyzed. Distance to a road, distance to housing, and topographic slope were identified as the major determinants of ignition frequency. They used logistic and Poisson regression analyses to model ignition occurrence and frequency as a function of the dominant covariates. They reported a $70 \%$ agreement in the spatial variability of ignition likelihood and $45 \%$ of the variability in ignition frequency.

Few models account for the spatial interaction of the anthropogenic factors that predict wildfire ignition probability and account for both fuel loads and ignition sources. Sadasivuni et al. (2013) developed such a model, wherein a gravity model was used to measure the interaction among cities. The city interactions provided a measure of movement of people, which was used as a model for wildfire ignition. The ignition distribution was then coupled with a fuel layer, obtained from the vegetation age-species combination, to predict the wildfire hazard in southeastern Mississippi. The model predictions were validated using historic wildfire data and compared with road-density model predictions (Gilreath 2006). The study concluded that population and road-density models capture different aspects of the human impact on wildfires and need to be combined, along with other human activity patterns, to obtain an improved model.

Several versions of the spatial interaction models have been developed for modeling socioeconomic activities based on Tobler's (1976) first law, which is commonly referred to as "gravity model" (Kathrin 2011). One of the most important variables in this model is the specification of the "distance matrix" or "proximity." It is expected that distance in a real world environment depends on the distance along the transportation corridors (Ayeni 1979; Faghri et al. 2001), and not the Euclidean distance. However, spatial interaction models available in the literature use Euclidean distance, and calibrate the distance matrix exponent to improve predictions (Huff 1963; Fotheringham and O'Kelly 1989; Porojan 2001; Chan 2011). Several other models use various constraints to model the anisotropic ${ }^{2}$ nature of the interactions (Openshaw 1998; Wilson and Burrough 1999). For example, the effect of intervening opportunities on traveler's behavior (Stouffer 1940) is included using a multiplicative constant obtained using probabilistic theory (Rietveld and Nijkamp 2002; Stillwell et al. 2010). One of the issues associated with such models is the calibration of model coefficients. Secondly, they employ ad hoc weight functions for modeling multi-criteria interaction (Sadasivuni et al. 2009). In addition, McCormack (1999) pointed out that the gravity model cannot be applied in general for all interaction. For example, the model works well for traffic analysis using longer trips, but not for shorter trips.

Holmes et al. (1994) provided a literature review of the partial differential equation models applicable for ecological modeling. They concluded that population models have the ability to describe the spatial variation of fundamental elements of ecology, ranging from individual behavior to species abundance, diversity, and population dynamics. They note that while there has been an explosion of theoretical advances in partial differential equation models, this work has been generally neglected in mathematical ecology textbooks. Shields (1997) introduced the flow metaphor for the movement of people, commodities,

\footnotetext{
${ }^{2}$ Anisotropy refers to variation in the interaction along a specific direction. In this study, anisotropy specifically refers to the nonuniformity of the wildfire potential due to cities along the transportation corridors with high traffic volume.
} 
capital, and information across geographic space, and related them to vector or direction and movability or diffusion of fluids.

\subsection{Objective, Modeling Philosophy, and Approach}

The objective of this research is to develop and validate a robust spatial interaction model to predict anthropogenically-initiated accidental and incendiary wildfire ignition probability. The overarching goal of this project is to develop a geographic information system (GIS) tool to obtain the ignition potential map of an area, which can be combined with meteorology and fuel type and distribution maps to assist in wildfire management and prevention. This research builds on the previous wildfire ignition prediction modeling efforts by the authors (Gilreath 2006; Grala and Cooke 2010; Sadasivuni et al. 2013) to develop a state-ofthe-art model that can depict a range of human activity patterns.

The first step in development of such models is to understand the underlying mechanisms governing the interaction of the wildfire events with the anthropological factors. Wildfire observations systematically remind us that wildfire ignition distribution occurs in a hierarchal process, originating from the initiation centers and diffusing spatially along preferential directions. Literature emphasizes cities and population areas as the initiation centers; however, they fail to define the diffusion direction. Furthermore, the definition of spatial distance from the initiation center is a complex one, as the diffusion seldom occurs across the Euclidean distance, but is rather aligned with the curvature of the transportation corridors.

In this study, a model for anthropogenically-initiated wildfire ignition prediction is developed by assuming an analogy between the movement of people and fluid dynamics equations. The works of Holmes et al. (1994) and Shields (1997), as discussed above, motivate the use of a fluid dynamics analogy. The fluid dynamics analogy is justified as their governing equations provide a more versatile modeling of physical processes using convection, diffusion, pressure-gradient terms compared to other commonly used equations in applied mathematics, such as Kirchhoff's law (Oldham 2008) or population model (Holmes et al. 1994). Kirchhoff's law provides equations for the movement of electric current due to voltage potential difference in series or parallel circuits. The same phenomenon can be represented through fluid dynamics equations by replacing voltage potential with pressuregradient. Fluid dynamics equations can apply to population models if the pressure gradient terms are neglected.

Our modeling philosophy is based on three assumptions: (1) the movement of people can in general be represented by flows between cities or population areas; (2) the direction of the movement of people is aligned with the roads (or intermodal transportation corridors), and is concentrated along the high traffic volume roads; and (3) roads provide the access points to the wild/woods for people with incendiary motive, and they are expected to move away from the roads and into the woods in a pattern similar to fluid diffusion. As depicted in Fig. 1, the factors influencing wildfire ignition potential are grouped as "global" (population interaction) and "local" (parameters of transportation corridors) variables. The global variables, or global human interaction patterns, can be best related to a pressure gradient term, and are modeled using a gravity term following Sadasivuni et al. (2013). The local variables are modeled as convective/diffusive fluxes across the local boundaries. The roads and traffic volume provide the convection direction, and allow modeling of the anisotropy that is present in global human interaction patterns. The transportation corridors act as diffusion sources and are used to model the dispersion behavior of the individuals that cause the accidental and incendiary wildfires.

In the following section, the correlation between the historic wildfires and transportation corridors is studied using 18 years of data collected in southeastern Mississippi. In Sect. 3, an urban fringe, transportation corridor convection-diffusion model (CDM) is developed for wildfire ignition potential prediction, the model coefficients are calibrated from the observational data, and analytic validation of the model is performed. In Sect. 4, the CDM model is applied to the development of a wildfire hazard prediction map of southeastern Mississippi. The predictions are compared with gravity model predictions

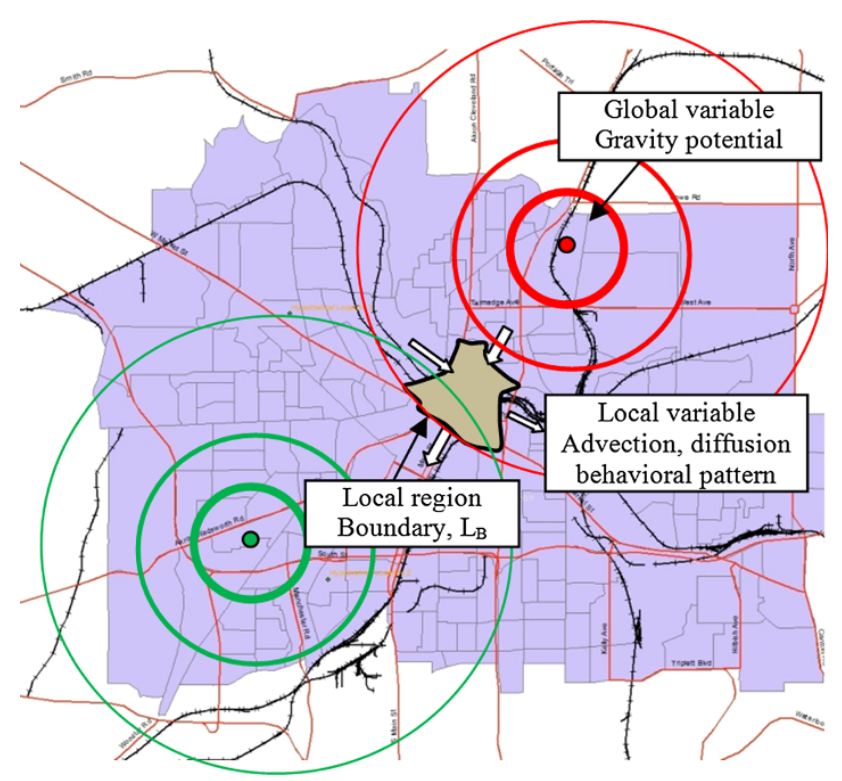

Fig. 1 Schematic diagram showing the proposed ignition potential prediction model 
(Sadasivuni et al. 2013), and validated against historic observations during summer and winter seasons. Conclusions are drawn and future work is discussed in Sect. 5.

\section{Wildfire and Transportation Corridor Interaction Mechanism}

The study area shown in Fig. 2 a includes the southeast region of Mississippi, located between longitude $88.4^{\circ}-$ $89.83^{\circ} \mathrm{W}$ and latitude $30.8^{\circ}-32.92^{\circ} \mathrm{N}$. This area includes 22 counties that are considered as the southeastern fire district of Mississippi. It has coastal plains that in mid-coastal regions are characterized by gentle hill topography, is well drained, and has diverse soils. The southern part of this study area is the lower coastal plain, which possesses welldrained forest soils and deep sandy alluvial soils. The region has 60-70 cities and towns with populations that range from just 120 to 72,000 people. The most populated cities of Gulfport $(72,000)$ and Biloxi $(50,000)$ are located along the Gulf coast. In the interior of the region, the largest cities are Hattiesburg with 45,000 people and Meridian with 40,000 people. It is clear that humaninduced wildfires are a major driver of detrimental change in the region's biodiversity (Fowler and Konopik 2007).

\subsection{Observational Data}

The data available in this region include: line files for designated highways and county roads; a line file of railroads obtained from the Mississippi Bureau of Transportation statistics; point locations for wildfire occurrences from the Mississippi Forestry Commission for the 18 years from 1992-2009; and real traffic volume data from the Mississippi Department of Transportation Planning Division (MDOT). The analysis focuses on the interaction of wildfires with roads, railroads, and cities. For the analysis of the road interaction, the designated highways have been partitioned into primary and secondary roads. The primary roads include interstate highways and federal highways, whereas the secondary roads include state highways and major roads (that is, paved marked roads). For the city interaction analysis, road density including both designated and county roads, traffic volume, and city population are used. A fuel layer based on the vegetation age-species combination derived from Landsat Thematic Mapper image mosaics and scenes from the Spatial Information Technology Laboratory at Mississippi State University Department of Forestry was analyzed previously (Openshaw 1998; Sadasivuni et al. 2013), and made available to the authors.

The historical wildfire data were analyzed for better understanding of the distribution pattern of anthropogenically-initiated wildfire events in the southeast
Mississippi region. Analysis focused on: (1) causes of wildfires; (2) yearly variations; (3) wildfire sizes; and (4) monthly and seasonal variations. The data analysis consisted of a topological analysis of the vector or raster objects to understand their spatial structure or correlation. For this purpose the following topological tools available in ArcGIS were used: (1) adjacency-which is the zone of influence on either side of an element, for example, calculation of buffer zone; (2) distance-which is the Euclidean distance between two points of interest; (3) neighborhood - which interpolates data features to raster objects in order to obtain a continuous response surface; and (4) map algebra functions to calculate complex mathematical functions. Interpolation was performed using moving window/kernel density estimation. The size of the window was chosen using an iterative method to maintain local variation without over-generalizing the density estimation following Cooke et al. (2007). For this purpose, kernel sizes from $200 \mathrm{~m}$ to $10 \mathrm{~km}$ were tested. The large kernel sizes produced a near uniform response surface and failed to capture the local variation patterns. On the other hand, small regional patterns were lost for smaller kernel sizes and lead to regions of zero road-density as the roads are sparsely distributed. The optimal window size was found to be $4 \mathrm{~km}$, which is used in the analysis.

\subsection{Wildfire Cause and Area Analysis}

The data show around 19,200 wildfire events for the 18 year period, and shows peaks in the years 1999-2000 and 2006-2007. The higher frequency in these years correlates very well with the wildfire drought index in the region (Sadasivuni 2013). The reported cause of wildfires included: arson (64\%), prescribed burns due to debris burning and equipment maintenance (32.75\%), lightening strikes $(0.96 \%)$, smoking $(0.7 \%)$, children $(0.56 \%)$, railroad $(0.53 \%)$, and camp fires $(0.28 \%)$. Note that equipment maintenance fires are classified as prescribed fires, since it is expected that maintenance occurs in a controlled environment under supervision. Since our focus is on human-initiated accidental and incendiary wildfires, only wildfire events due to arson, smoking, children, railroads, and campfires are considered for the rest of the analysis, which account for 12,701 wildfires (66 \% of the total).

The distribution of wildfire size shows that fire sizes range from 1 to 50 acres. The peak frequency is in the $1-5$ acre range, and the mean fire size is 18.3 acres. The fire sizes show a log-normal distribution (log scale with base e). Arson fires are mostly distributed in the southern and southeastern part of the region, which are the most populated regions. Prescribed wildfires are observed all over the region, and are distributed mostly along the urban fringe 


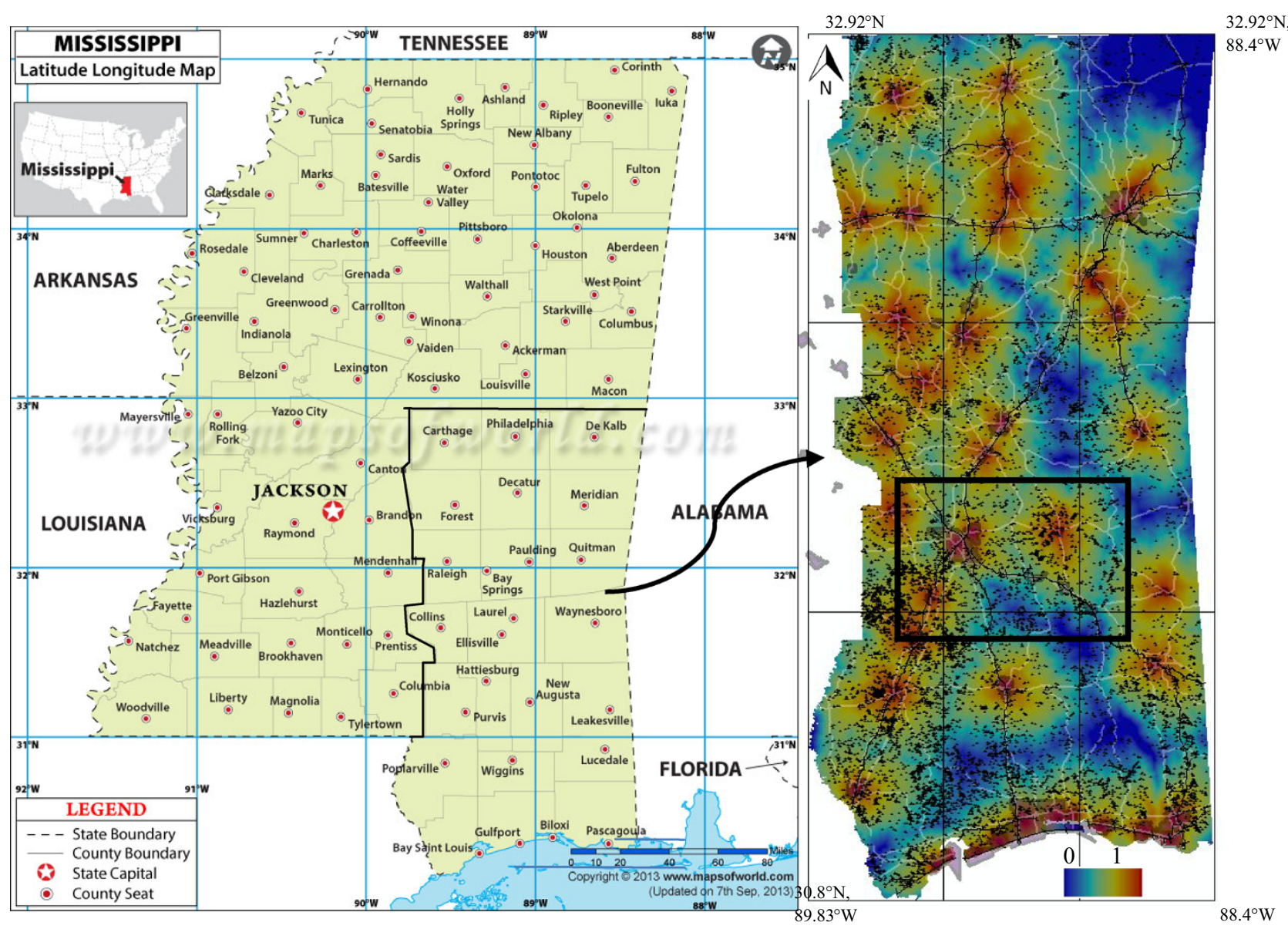

(a)

(b)

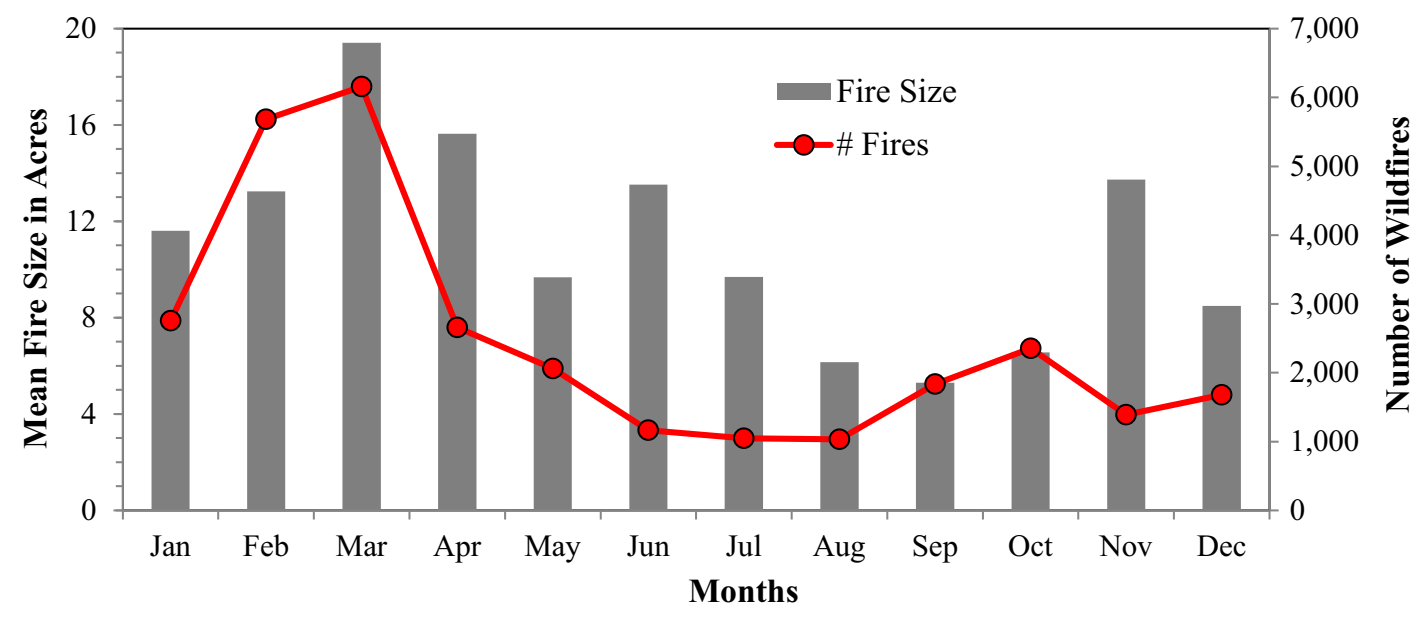

(c)

Fig. 2 a Southeastern Mississippi study area. b Primary roads (white lines), railroads (black lines), cities (shaded), and wildfire incidences for years 1992-2009 (black symbols). The background color is the normalized gravity model wildfire ignition potential predictions. Black horizontal and vertical grid lines show the quadrats for the railroad interaction analysis. The boxed region is the Hattiesburg area used for the preliminary ignition model validation. c Variation of average wildfire size and number of wildfires with months in the past two decades 
and interconnecting roads. These fires burn an area between 1 and 5 acres on average. Sadasivuni (2013) provides details on scale and frequency.

\subsection{Seasonal Analysis}

Grala and Cooke (2010) and Dutta (2010) categorized the seasons in the region as winter-spring (January-April), summer (May-August), and fall-winter (SeptemberDecember). We have categorized the entire year into summer and winter seasons, each of 6 months duration. Summer from April through September, and winter from October through March. The winter season includes 12,757 wildfires, which is $66 \%$ of the total, and the summer season includes 6,443 wildfires, which is $33 \%$ of the total. The wildfire frequency and size distribution plotted by months of the years in Fig. 2b shows a peak in early and late winter (October and March) and both frequency and size are lower in summer. It is interesting that June, July, and November have large average fire sizes although the number of fires is lower than average. Cooke et al. (2007) analyzed the monthly wildfire frequency and area distribution in the region for the years 1991 through 2005. They observed a cyclical nature in wildfire frequency and area, with peaks in winter and lows in summer. They also noted higher than average summer fire areas in some years. A most notable pulse occurred in 2006 when the wildfire fuel level increased due to hurricane Katrina in 2005. The study also plotted monthly wildfire frequency along with precipitation observations. They observed highest precipitation in early and later winter, when the wildfire frequency is highest. Winters should be less prone to wildfire because lower evaporation coupled with higher precipitation creates more moist and wet fuel conditions. The higher wildfire frequency for winter fires obtained by Cooke et al. (2007), suggests that winter fires have more human involvement than summer fires.

Figure 3 shows the area-weighted observational data distribution of wildfires in the region. Annual observational data for the southern fire district of Mississippi shows that the fires are more concentrated in the highly populated southern part of the region, and in the northern part of the region around the city of Meridian. Winter fires are more concentrated in and around cities and along the roads, and show sharp distinction in high and low hazard regions compared to the annual fires. Summer fires are geographically more evenly distributed than annual fires with some concentration in the southwestern and central part of the study area.

\subsection{Correlation of Wildfires with Roads}

Analysis shows that up to $60-70 \%$ of the wildfires lie within $1 \mathrm{~km}$ buffer zone of primary roads and up to $80 \%$ lie within $2 \mathrm{~km}$. These results are in accordance with Grala and Cooke (2010) analysis. The distribution of the wildfire event percentages close to primary roads in Fig. 4 show a peak value of $25 \%$ within $250 \mathrm{~m}$ of the road, a value of about $15 \%$ within $250-500 \mathrm{~m}$, and rapid decay beyond $500 \mathrm{~m}$. The wildfire distributions along the secondary roads are almost uniform. Secondary roads usually have less traffic volume than primary roads and are less likely to be ignition sources (ORNL 2011). Nonetheless, a decay in the fire distribution should have been observed. One possible reason for the absence of the expected decay could be the close spacing between secondary roads compared to primary roads, which may lead to quicker response of firefighters and efficient containment of the fires. Another reason is the utilization of "woods" roads and other tertiary vehicle access corridors that are seasonally available to vehicles but not mapped in the line file for roads. For the purposes of this study, only the primary roads are considered for the modeling of wildfire ignition. Future work will focus on further analysis of the correlation of wildfires with secondary and tertiary roads.

\subsection{Correlation of Wildfires with Railroads}

In the study area, the railroads run parallel to the primary roads, thus the distribution of wildfires along the railroad buffer zones are similar to that observed for the roads. Thus, such analysis does not explain the interaction of railroads with wildfires accurately. To evaluate the effect of railroads, the study region was divided in quadrats, and the wildfire events per unit length of the railroad and roads were computed. The results, excluding the quadrats with small railroad lengths, show that there are $30 \%$ more wildfire events in the multimodal transportation corridors than the road corridors alone, as shown in Fig. 4b. Note that, the presence of railroads leads to $30 \%$ higher wildfire events, but the fires due to railroads is only $0.53 \%$. This is because, the length of railroads are significantly lower than that of the roads. The European Commission report (EC 2012) suggests that the additional fires due to railroads are expected due to sparks emitted by train brakes, fall of catenaries, or linked to the operations of the trains, such as smoking by railway employees or passengers.

\subsection{Correlation of Wildfires with Cities}

Gilreath (2006) road-density analysis in the same region for a 15-year period dataset (1991-2005) showed that the wildfire events correlate well with medium road density, that is, areas on the outskirts of cities. This study is extended to include an 18-year database, and the results are almost identical to Gilreath's results as shown in Fig. 5a. In 
Fig. 3 Normalized distribution of area-weighted historic wildfire hazard for 1992-2009: a annual, b summer, and c winter in the southeast Mississippi region. Normalized distribution of the wildfire hazard predicted by: $\mathbf{d}$ roaddensity, e Gravity, and f CDM models. The legends for the plots are shown in $\mathbf{a}$ and $\mathbf{d}$ (a)

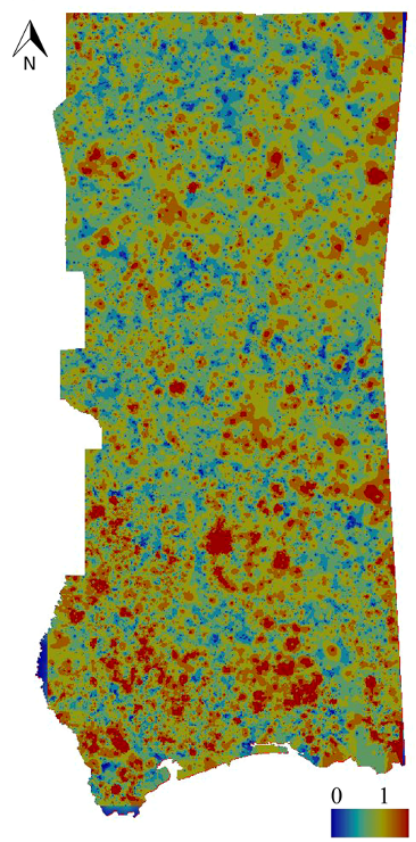

(d)

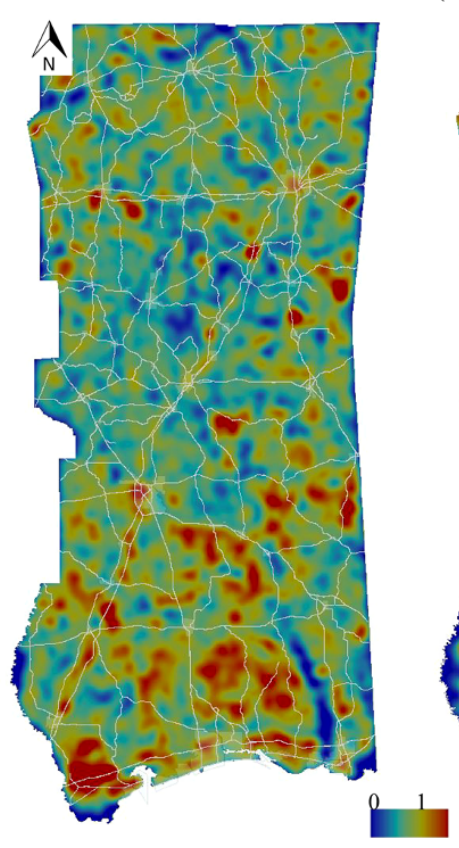

(b)

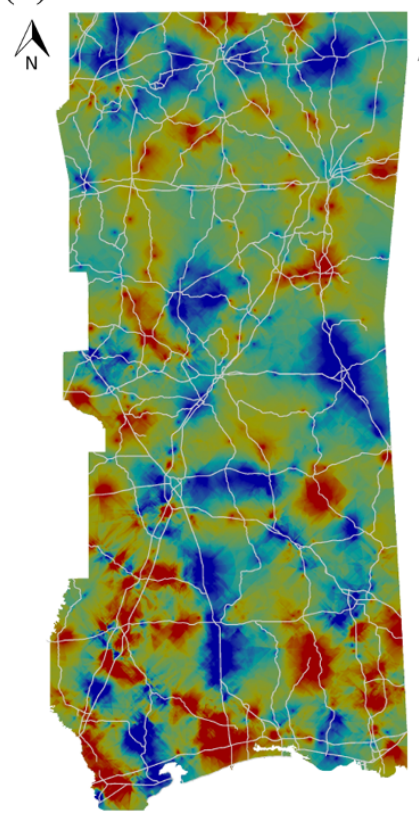

(c)

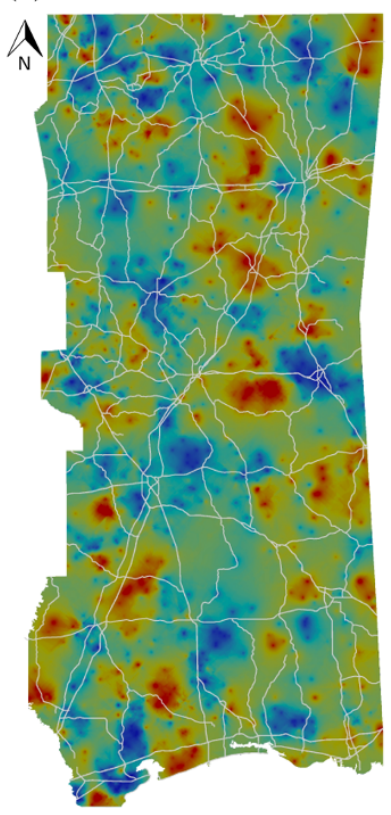

(e)

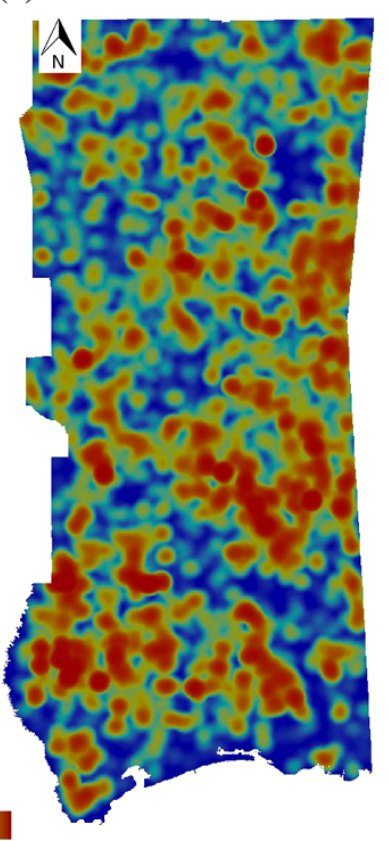

(f)

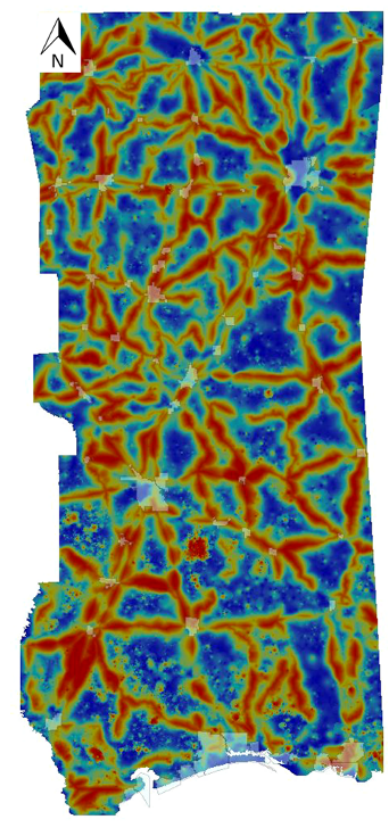

addition, the road densities are also related to the normalized distance (using city radius) from the city center. The variation of the wildfire events along a city's outer radius helps to evaluate the wildfire ignition potential, which is dampened inside the city as shown in Fig. 5b. As shown in Fig. 6, wildfire events are mostly aligned within $2 \mathrm{~km}$ of primary roads with high traffic density $\left(V_{t} / L_{r o}\right)$. Thus, traffic density can be used to obtain anisotropy in the city wildfire ignition potential.

\section{Wildfire Ignition Model Using Convection-Diffusion Analogy}

The model uses vertical and horizontal integration of anthropogenic factors and fuel availability to derive the wildfire hazard prediction model, similar to Sadasivuni et al. (2013). The vertical integration of assessment links factors that have separate impacts on the wildfire potential, whereas the horizontal assessment integrates the similar 


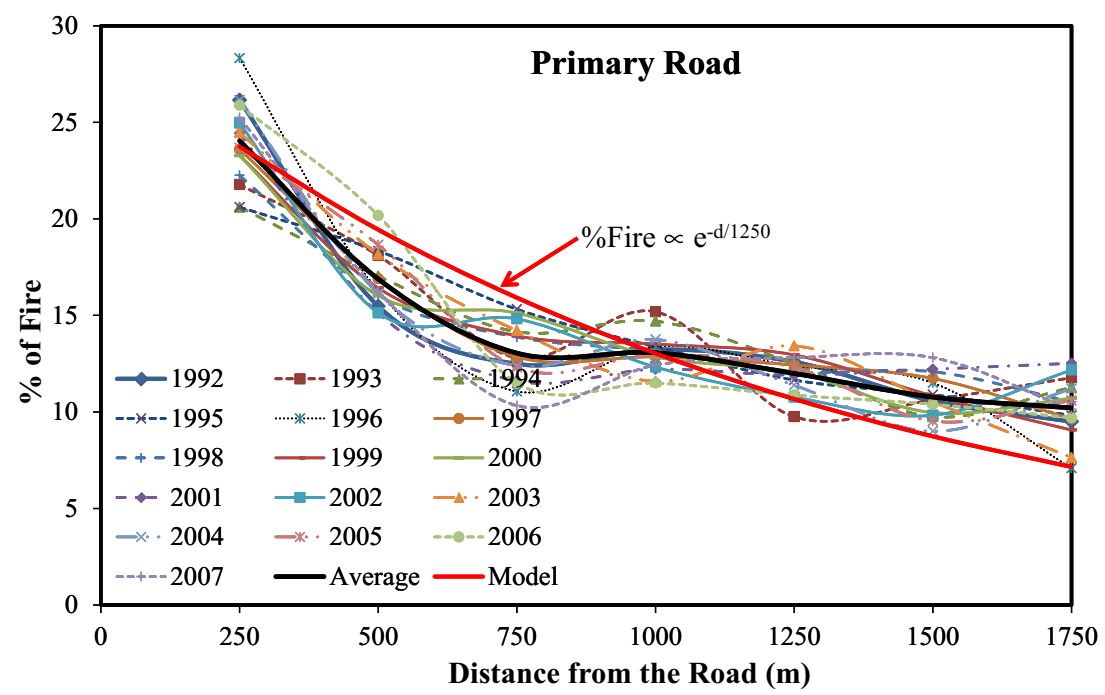

(a)

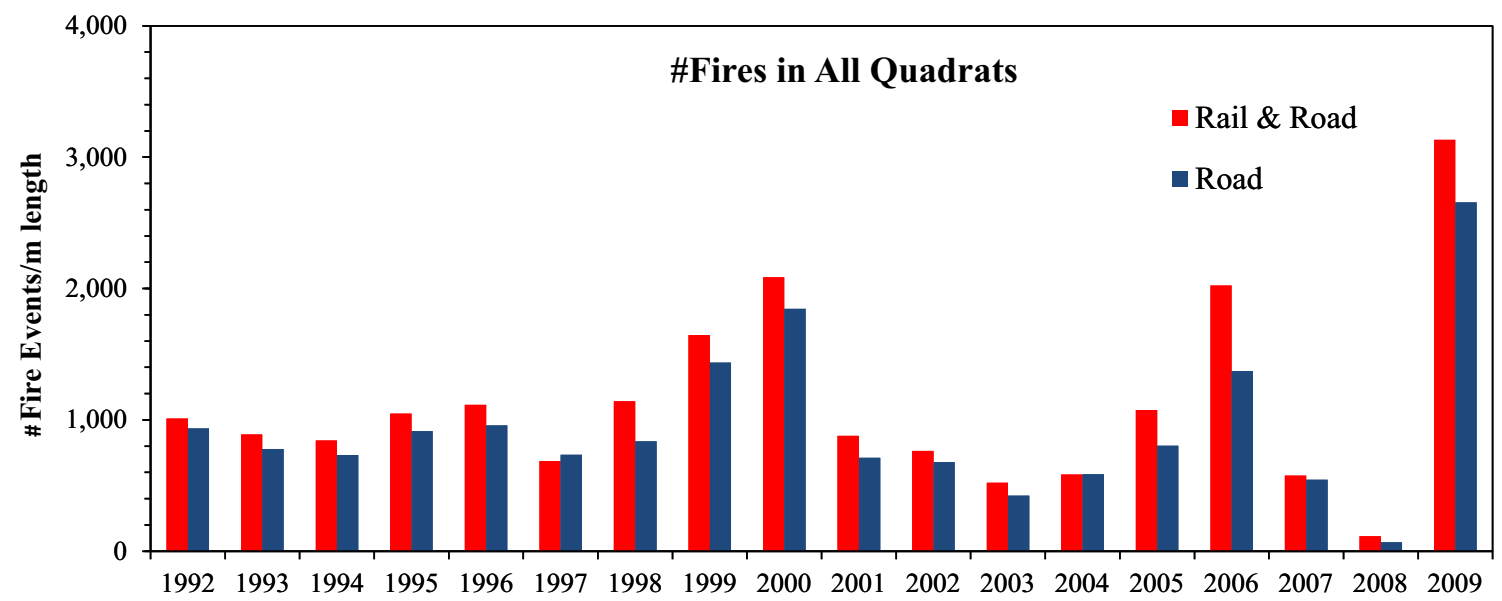

(b)

Fig. 4 a Distribution of wildfires along the primary roads for the years 1992-2009. The data for years 2008 and 2009 are not presented as the numbers of wildfires were too small to obtain reliable statistics. The road buffer zones are from $250 \mathrm{~m}$ to $1.75 \mathrm{~km}$. Figure also shows

impact factors into a single overall assessment. The vertical assessment is performed using a multiplicative operation, and the horizontal assessment is performed using an additive operation. A flowchart, which demonstrates the horizontal and vertical assessments used in the study, is shown in Fig. 7, and key points are summarized below.

- The two primary factors influencing wildfire hazard potential are fuel potential $\left(\phi_{f}\right)$ and ignition potential $\left(\phi_{i}\right)$. These factors are integrated using vertical integration.

- The fuel potential may have spatial and temporal variations. The spatial distribution is primarily governed by the fuel load distribution, whereas the temporal distribution depends on the climate, season, and drought index in the region (Cooke et al. 2007). the averaged profiles and the exponential potential function $\left(\phi_{R O}\right)$ model. b Wildfire events per unit length of the intermodal transportation and road corridors are compared in the study region for the years 1992-2009

These temporal effects are not included in this study; hence their integration is not discussed.

- The ignition potential is a function of space, and depends on the anthropogenic factors or movement of people in the region described by the "local" and "global" influencing factors. The global factors are the cities. The city parameters that are identified to be the influencing factors in Sect. 2.6 are: proximity $(D)$ to city; population $(P)$; density of the corridors $\left(L_{r o}\right)$, in particular that of the road represented by subscript ro. Local influencing factors are the transportation corridor parameters, such as proximity to transportation corridors $\left(d_{T C}\right)$, curvature of the transportation corridors, and traffic volume $\left(V_{t}\right)$. 
Fig. 5 a Road-density at the wildfire locations are shown as bar chart for wildfires in years 1992-2009. The line plot shows the distribution of the roaddensity with respect to the normalized distance (using city radius) from the city center. Analysis is performed using three cities of variable size in the central region-Hattiesburg, Laurel, and Ellisville.

b Variation of the wildfire ignition potential (events) inside the city. Also shown are the gravity model wildfire ignition potential estimates for a city, and the derived dampening function

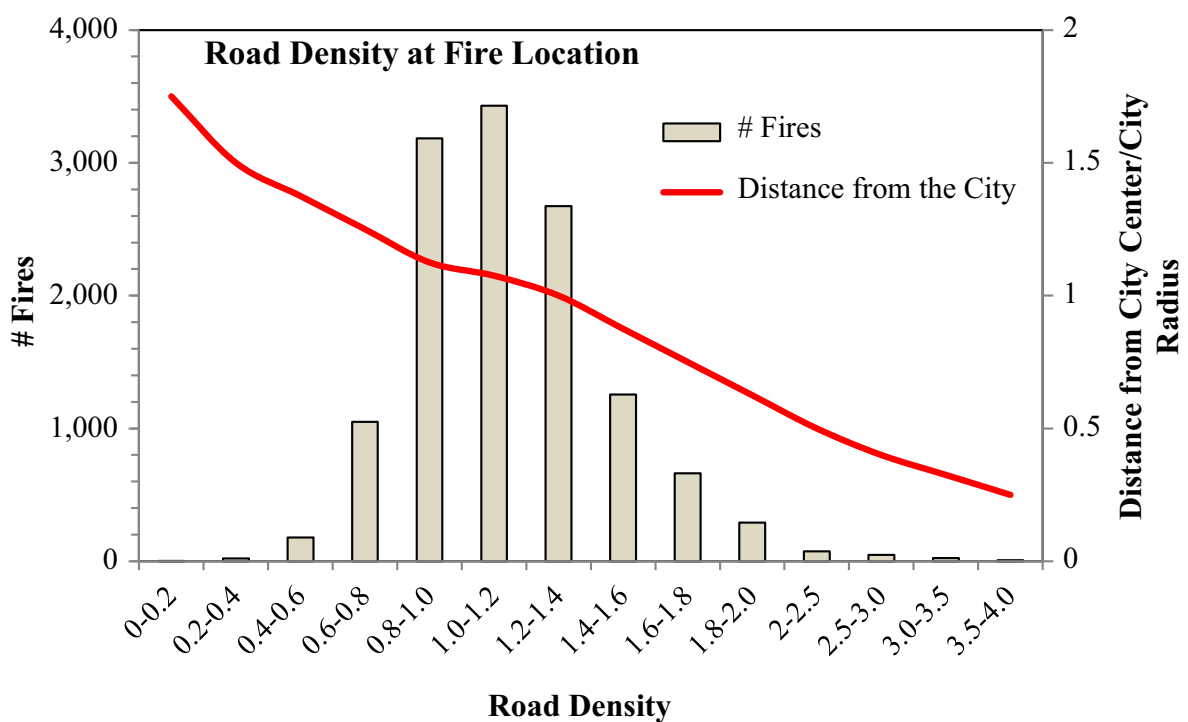

(a)

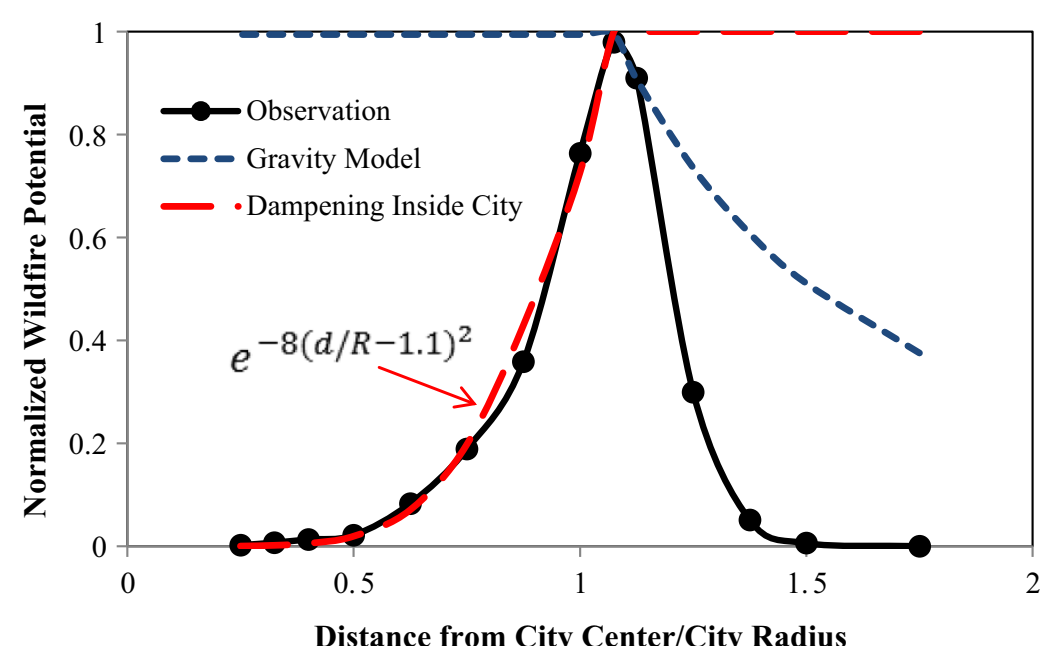

(b)
- The global and local influencing factors are assumed to be independent of each other, and are integrated using vertical assessment.

- The ignition potential due to population is modeled as a gravity term that is vertically integrated with the roaddensity effect. The traffic volume effect is more prominent close to the cities and causes nonuniformity in the city ignition potential distribution. The traffic volume effect is modeled as convection term and horizontally integrated with the population gravity model.

- Ignition potential along transportation corridors, such as roads and railroads is modeled as diffusive fluxes across the local region boundaries $\left(L_{B}\right)$. They are expected to have similar impacts, thus are integrated using horizontal assessment.
The resulting convection-diffusion model (CDM) for the wildfire hazard potential prediction is:

$$
\begin{aligned}
& \phi(x, y, t)=\phi_{f}(x, y, t) \times \underbrace{\phi_{i}(x, y)}_{\text {City ignition }} \\
& \phi_{i}=\underbrace{\phi_{c}}_{\text {Transportation corridor ignition }} \times \underbrace{\phi_{\text {Pop }}}_{\text {Population ignition }} \times \underbrace{\phi_{T C}}_{\text {Road density }}+\underbrace{\phi_{T r}}_{\text {Traffic volume ignition }} \\
& \phi_{c}=\underbrace{\phi_{R}}_{\text {Road ignition }}+\underbrace{\phi_{R A I L}}_{\text {Rail ignition }}
\end{aligned}
$$

The following section briefly summarizes the derivation of the ignition potential terms based on the local and global influencing parameters. Readers are referred to Sadasivuni (2013) for details of the derivation. 

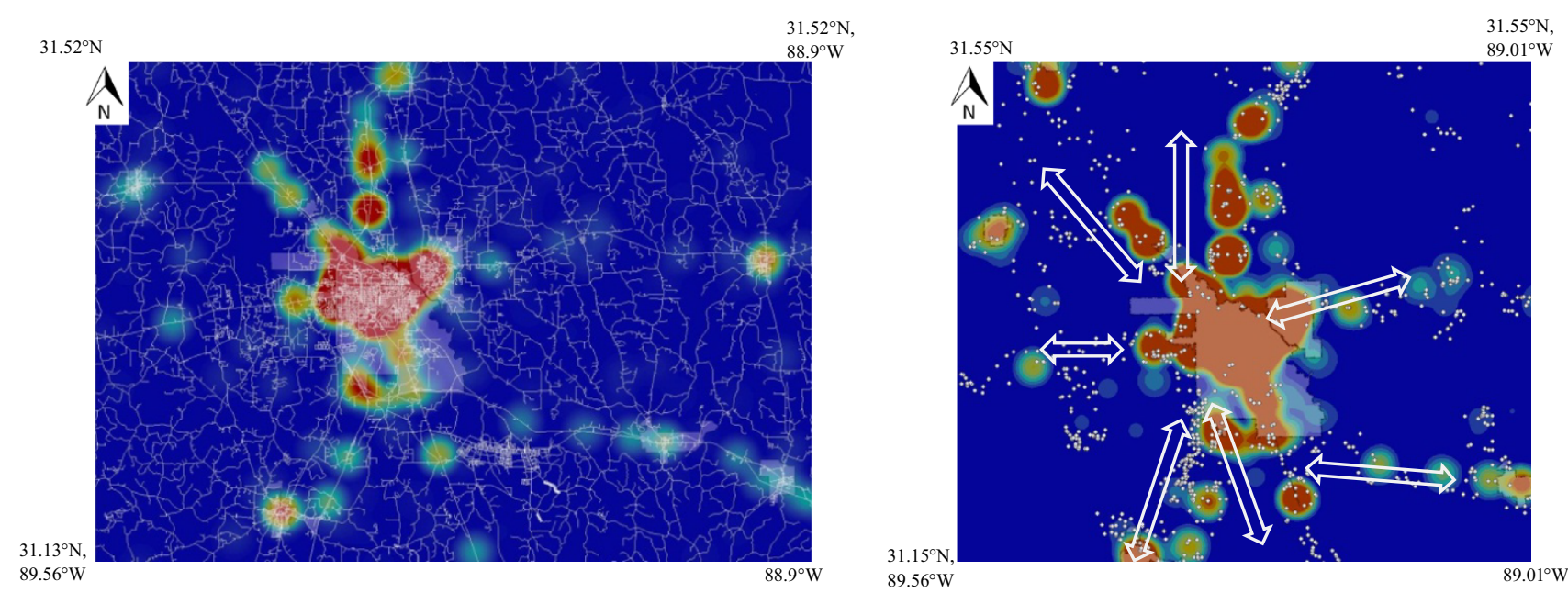

Fig. 6 Traffic volume and primary and secondary roads (left) and traffic volume by road-density (right) are shown for Hattiesburg city area. The arrows highlight the uneven spatial distribution in the city potential field due to the normalized high traffic volume. The anisotropic potential pattern shows a good correlation with the wildfire events in years 1992-2009 (white dots)
Fig. 7 Flowchart

demonstrating convectiondiffusion modeling of wildfire ignition and risk potential

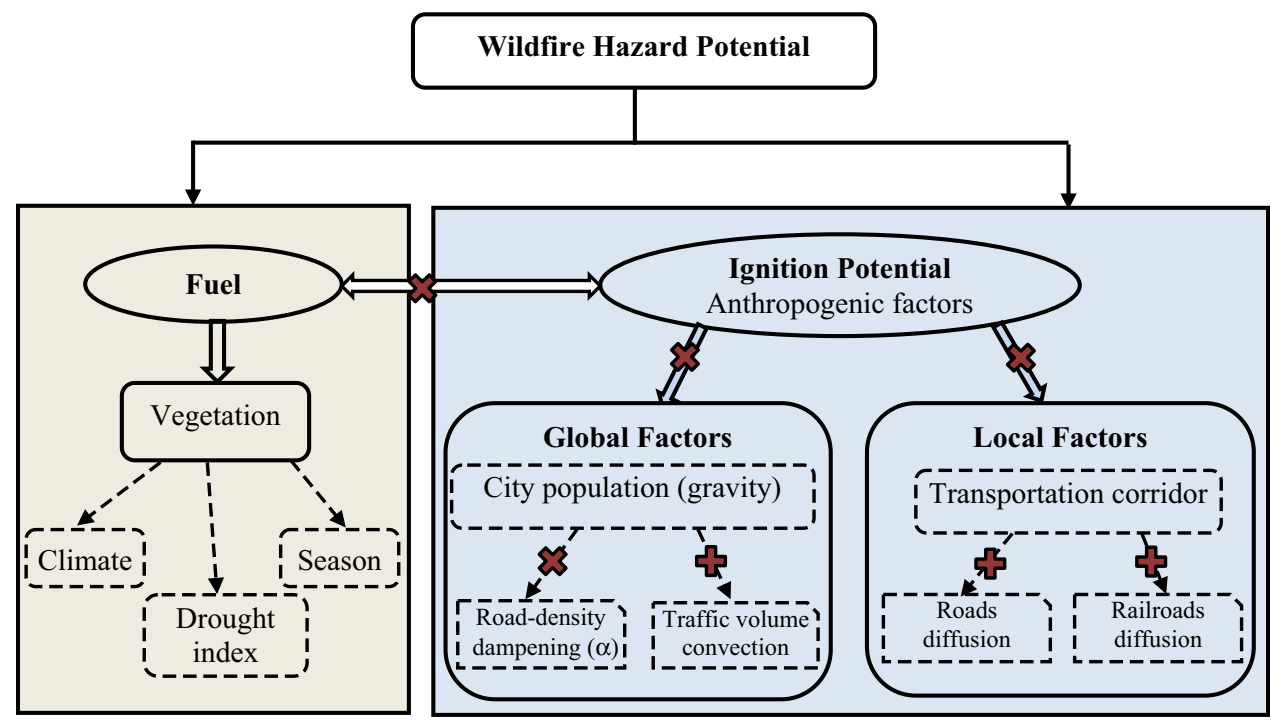

$\alpha=\mathrm{e}^{-8(D / R-1.1)^{2}}$

As expected $\alpha<1.0$ for $D / R \leq 1.1$, and $\alpha=1.0$ for $D / R>1.1$, where $R$ is the radius of the city.

The effect of traffic volume is modeled as convection along the roads as a summation of fluxes (or magnitude of human interaction) across the local region $(B)$ boundaries $L_{B}$ as below:

$\phi_{T r}=V_{n}\left(\frac{V_{t}}{L_{r o}}\right) \frac{\delta \phi}{\delta n}=\sum_{B} \frac{1}{L_{B}} \phi V\left(\frac{V_{t}}{L_{r o}}\right)$

$\phi_{P o p}=\alpha \frac{P}{D^{2}}$

The gravity ignition potential due to the cities is modified to include a dampening inside the city as shown by the data in Fig. 5b. An exponential curve fit over the data, which gives: where, $V_{n}$ is the convection parameter normal to the region boundary, which is well represented by traffic volume by road density as shown in Fig. 6; $n$ is the direction normal to the boundary $L_{B}$ along the roads. One should expect high fluxes along the local boundaries aligned with the roads, 
especially those with high traffic volume, for example, the movements of people in and out of the cities are along the major highways. This convection plays an important role in generating an anisotropic behavior of the city's gravity ignition potential (refer to Fig. 6), aligned with the corridors with high traffic volume. Thus, the potential in Eq. 3 is dominant along the high traffic volume corridor direction $\left(\theta_{c}\right)$ as below:

$\phi_{T r}=\sum_{B} \frac{1}{L_{B}} \phi_{P o p} V_{n}\left(\frac{V_{t}}{L_{r o}}\right)=\frac{V}{\delta \theta} \phi_{P o P}=V_{T r}\left(\theta_{c}\right) \phi_{P o p}$

where, $V_{T r}$ is Gaussian distribution of the normalized traffic volume along $\theta_{c}$ as below:

$V_{T r}\left(\theta_{c}\right)=A \mathrm{e}^{-4\left(\theta-\theta_{c}\right)^{2} / \pi}$

where, $A$ is the amplitude of the distribution and is obtained from the data, that is, traffic volume normalized using roaddensity. In the study area considered in the article, $A$ ranges from 1 to 15 .

\subsubsection{Intermodal Transportation Corridor Potential}

The ignition potential due to transportation corridors, that is either due to road or rail, is modeled as diffusion across the corridors as:

$v \frac{\delta^{2} \phi_{T C}}{\delta d_{T C}}-\phi_{T C}=0$

The solution of the above equation is:

$\phi_{T C}=C \mathrm{e}^{-\sqrt{v} d_{T C}}$

where, $C$ and $\sqrt{v}$ are unknown model coefficients. A curve fit through the observation data for the road in Fig. 3a provides:

$\phi_{R}=\mathrm{e}^{-\frac{1}{1250} d_{r o}}$

where, $d_{r o}$ is distance from the road. Observation data show that the railroads usually run parallel with the roads, thus their effect on wildfire distribution cannot be estimated. However, presence of rails causes a $30 \%$ increase of wildfire potential over the roads. Thus the ignition potential due to railroads is assumed to be similar to that of roads, and account for the expected $30 \%$ higher potential as below,

$\phi_{R A I L}=0.3 \mathrm{e}^{-\frac{1}{1250} d_{r a}}$

where, $d_{r a}$ is distance from the rails.

\subsubsection{Ignition Potential}

Substituting the ignition potential components in Eqs. 1b$1 \mathrm{~d}$, the final form of the CDM model wildfire ignition potential is obtained as below:

$$
\begin{aligned}
\phi_{i}= & \sum_{\text {Cities }}\left[\left[1+V_{T r}\left(\theta_{c}\right)\right] \alpha \frac{P}{D^{2}}\right] \\
& \times \sum_{\text {Roads }+ \text { Railroads }}\left[\mathrm{e}^{-\frac{1}{1250} d_{r o}}+0.3 \mathrm{e}^{-\frac{1}{1250} d_{r a}}\right]
\end{aligned}
$$

\subsection{Analytic Validation of the Wildfire Ignition Potential Model}

The mathematical formulation of the model terms and the combined model is validated using an in-house Fortran code. The problem considered for the validation is a simplified case with two cities: one with $4 \mathrm{~km}$ city radius and 10,000 population and second with $5 \mathrm{~km}$ city radius and 20,000 population. One road was considered passing through the cities, and an additional road was considered which connected the cities. A railroad was also considered to demonstrate the intermodal transportation interaction effect. Calculations were also performed by supplying hypothetical high traffic volume along some of the roads. The domain size was considered to be $100 \times 100 \mathrm{~km}^{2}$ with coarse $1 \times 1 \mathrm{~km}^{2}$ grids.

Figure $8 \mathrm{a}$ shows the spatial distribution of the gravity ignition potential with city damping. As expected, the dampening function decreases the potential inside the city. Figure $8 \mathrm{~b}$ shows the ignition potential distribution along the road and railroad. As expected, the potential is high close to the road and decreases away from the road. The potentials are high at the intersection of the roads, which is a favorable result. The railroads show peak potential with lower values than the road, as expected. Figure 8c shows the combined potential due to roads and cities. As expected, the potential aligns along the road due to the inclusion of the diffusion parameter along the road. The peak potential occurs at the outskirts of cities along the roads. Figure 8d shows the effect of the traffic volume convection parameter on the city gravity potential. As expected, the potential shows anisotropy in the high traffic volume direction. The model shows higher potential along the road connecting the two cities than the other roads. Overall, the results suggests that the model terms are behaving as expected, and can be applied to a general or more complicated city-road network.

\subsection{Validation for Simplified Representation of Hattiesburg Area}

The wildfire ignition potential model is applied for a region close to the Hattiesburg area as shown in Fig. 9a. The selected area has a domain size of around $85 \mathrm{~km}$ in the $X$ direction and $51 \mathrm{~km}$ in the $Y$ direction. This region has 8 cities/towns with population varying from 45,000 for Hattiesburg to 603 for McLain. For the calculation using 


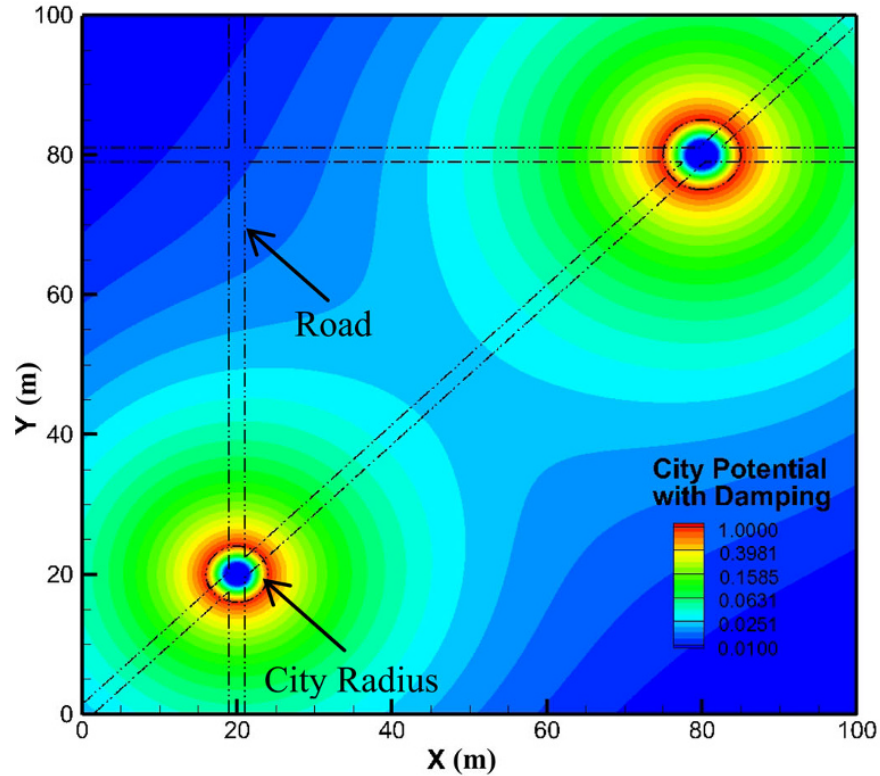

(a)

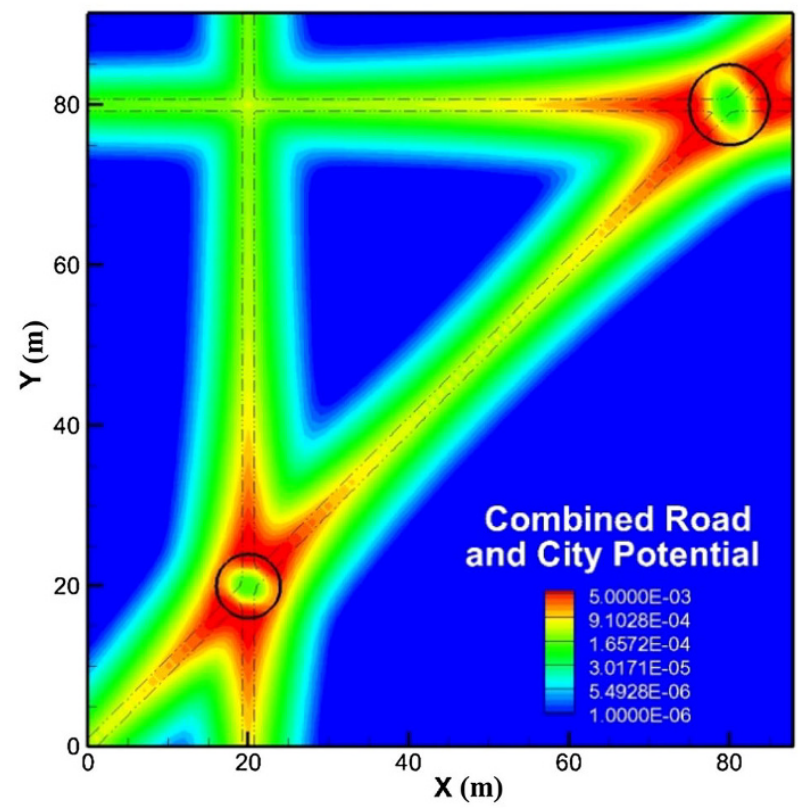

(c)

Fig. 8 Spatial distribution of a gravity ignition potential with city dampening, and b road and railroad corridor ignition potential. c, d Spatial distribution of the combined road and city ignition potential

the Fortran program, the cities are represented as circular regions as shown in Fig. $9 \mathrm{~b}$ with radius. The city radius was computed from the city area, which varied from $6.4 \mathrm{~km}$ for Hattiesburg to $1.3 \mathrm{~km}$ for Sumrall. The region contains several primary roads connecting the cities, which are segmented in 40 straight-line segments and imported to the Fortran code. The region has three railroad lines, which are segmented into 20 straight-line segments. The data

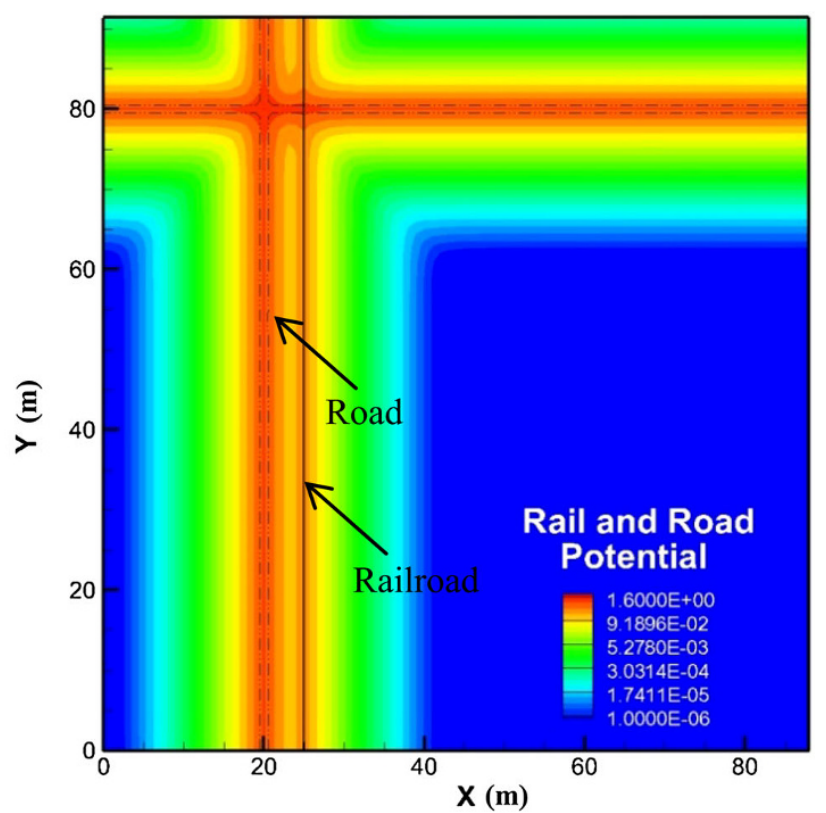

(b)

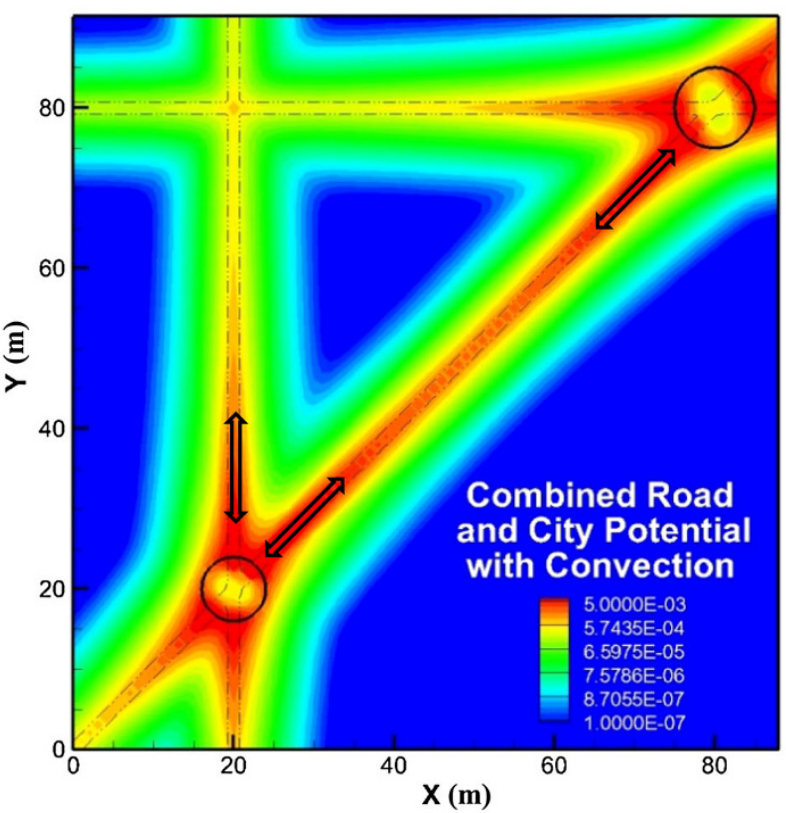

(d)

for two different city and road connection patterns. d Includes convection along roads with higher traffic volume, shown by arrows

show high traffic volume emerging mostly from Hattiesburg at $81^{\circ}, 130^{\circ},-70^{\circ}, 170^{\circ}$, and $-100^{\circ}$. $V_{T r}$ are estimated to vary from 2.0 to 8.0 , where 0 represents no effect of traffic volume, and the peak value estimated for the southeast Mississippi region is 15.0.

The calculation is performed using a 1,001 $\times 1,001$ grid, which allows $85 \mathrm{~m} \times 51 \mathrm{~m}$ resolution. As shown in Fig. 9c, high potentials are predicted in the city suburban 
areas, at road intersections connecting multiple cities and are aligned along the roads with high traffic volume. The potential is low inside the city due to dampening. The city potential is proportional to the population density, that is, high potentials are predicted at the edge of the densely populated areas Hattiesburg (348 people $\mathrm{km}^{-2}$ ) and Petal (302 people $\mathrm{km}^{-2}$ ), and lowest potential is predicted near New Augusta with the lowest density of 52 people $\mathrm{km}^{-2}$. The peak city potential at the edge of the city is expected to be proportional to population density from Eq. 2a, where $d$ is the radius of the city. Also note that Petal shows slightly higher potential than Hattiesburg, due to a combined gravitational effect on areas.
Fig. 9 a Map of the region around Hattiesburg area alongwith primary roads and railroads. The dots represent the wildfire incidences. b The depiction of the study region for the Fortran simulations. The cities are represented as filled circular regions, roads with solid black lines, and railroads with solid brown lines. The axis dimensions are in meters with respect to lower left corner. c CDM ignition potential prediction. The symbols show the 18 year fire events in the interior region. The circular region shows the clustered observed wildfires away from the cities and roads
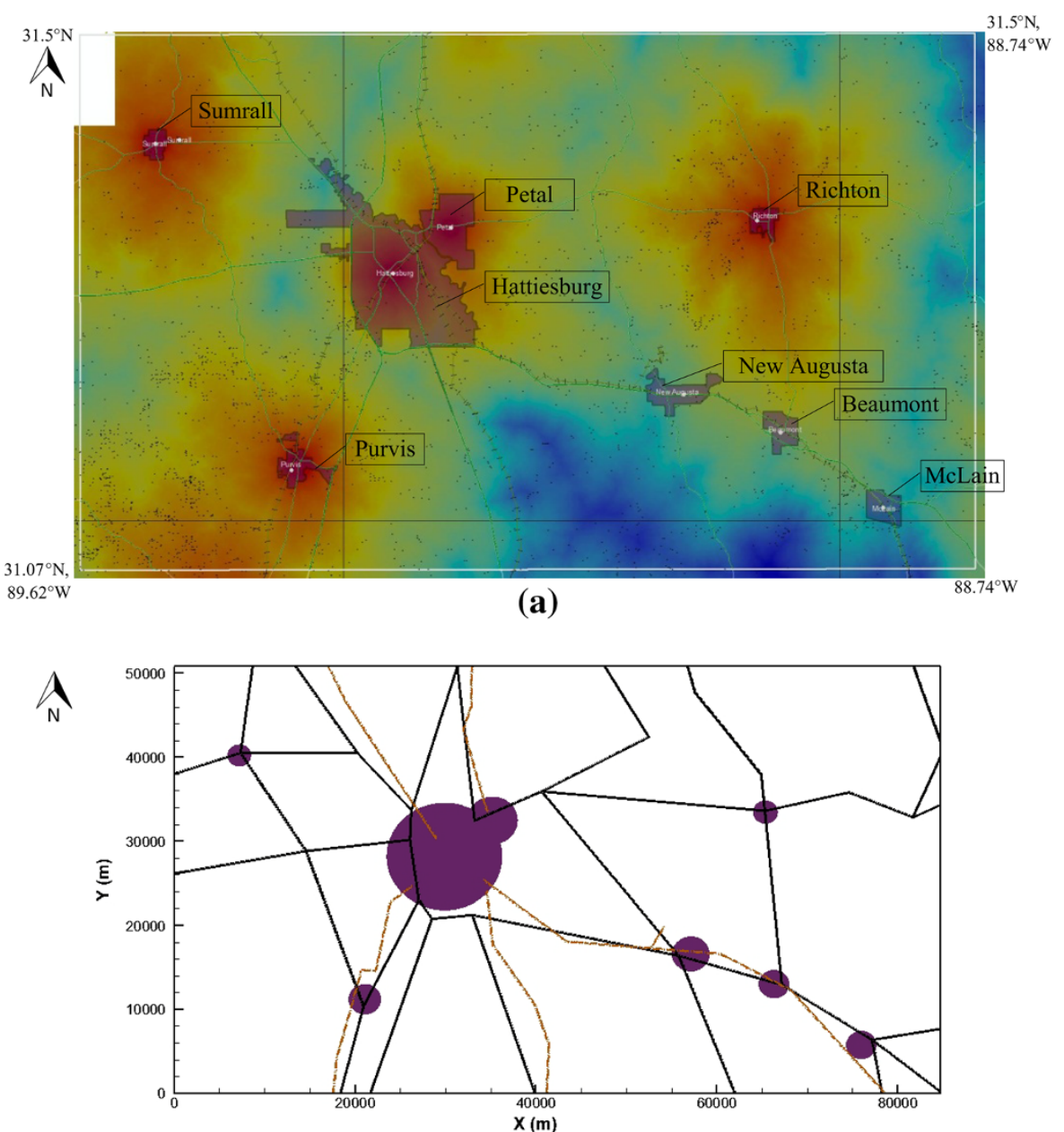

(b)

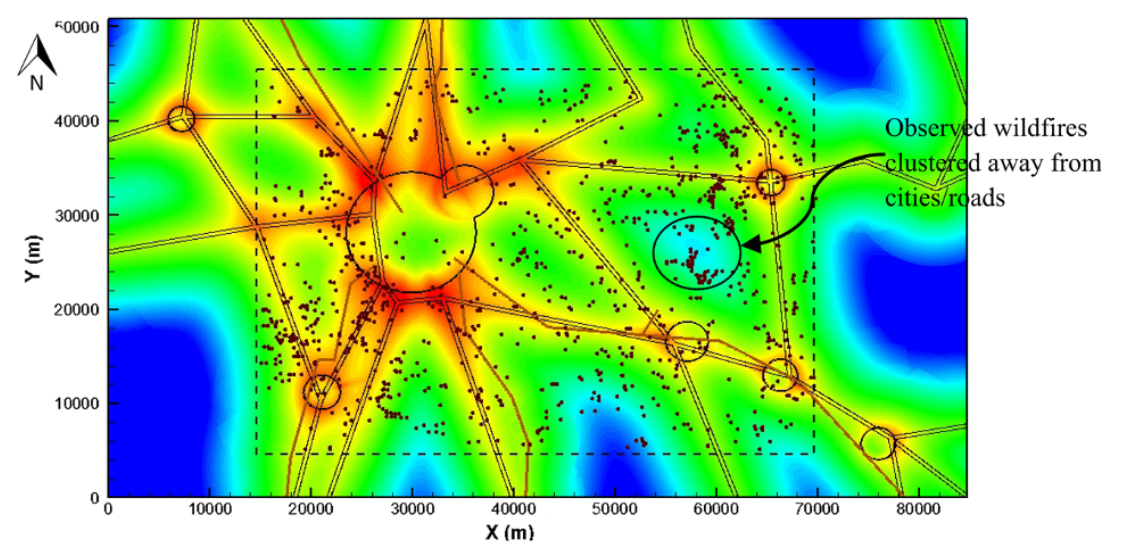

(c) 
Fig. 10 Number of observed wildfires (or fire frequency) in the quantile bins identified as Very Low fire hazard, Low fire hazard, Medium fire hazard, High fire hazard, and Very High fire hazard zones obtained using city, road, and combined (total) models

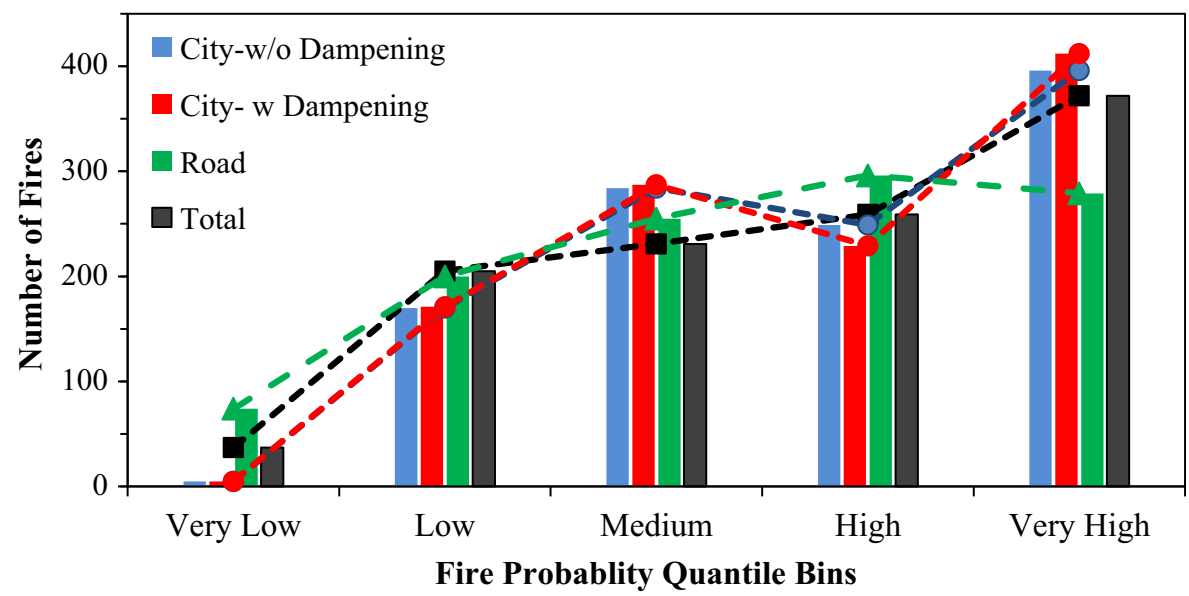

To obtain a quantitative measure of the accuracy of the model, quantile analysis is performed in a subregion of the study area as shown in Fig. 9c. A subregion is considered instead of the entire area, because the wildfire potential near the domain boundaries are expected to be less accurate as the influence of cities or roads outside the area are absent. Overall, the historical wildfire locations and the predicted wildfire potential show good qualitative correlations, as both show higher wildfire frequency in the city outskirts and along the primary roads. One notable exception is the cluster of historical wildfires around region $X=60,000$ and $Y=25,000$ as marked on Fig. 9c, which are away from both the cities and roads. Considering the location of the fires, they are expected to be due to recreational causes, such as camping/fishing, which are not included in the model.

For the quantile analysis, the wildfire potential is categorized into five hazard zones: Very Low, Low, Medium, High, and Very High. The quantile breaks are defined such that each class has an equal number of grid cells, that is, 250 thousand cells in each bin. The wildfire potential predicted by the city, road, and the complete model are then interpolated at the historical wildfire locations (1,104 events), and the number of wildfires (or wildfire frequency) within each five hazard zones were calculated. For this analysis, a good model should show more wildfire frequency in the higher hazard zones than the lower hazard zones. As shown in Fig. 10, the city potential shows a decrease in wildfire frequency from medium to high hazard zones, whereas the road potential shows almost uniform frequency in medium to very high hazard zones. The combined model shows the best prediction, as the wildfire frequency increases with the hazard. Overall, the predictions of the complete model are encouraging as up to $55 \%$ of the observed wildfires occur in the high fire hazard zones and only $3.5 \%$ in the very low hazard zone.

\section{Validation of the Convection-Diffusion Model (CDM) in Southeast Mississippi}

In this section, the implementation of CDM in ArcGIS and validation of the model are discussed. The validation study focuses on both qualitative and quantitative assessment of the CDM predictions using observational data, and comparisons with road-density and gravity model predictions.

\subsection{Implementation of the Convection-Diffusion Model in ArcGIS}

The CDM model was implemented in ArcGIS and combined with a fuel layer to predict the wildfire hazard of southeastern Mississippi. The fuel layer is derived from the vegetation age-species combination (refer to Sadasivuni et al. 2013 for details of fuel layer derivation, and ignition and fuel layer integration).

The implementation of the model primarily used tools available in the ArcGIS "Spatial Analyst" toolbox as listed below:

1. The centroid of each city in the study area was created using the "Feature to Point" tool, which creates a feature class containing centroid points from the polygon town/city features.

2. The Radius, $R$, for each city was computed from the area of the city as $R=\sqrt{\text { Area } / \pi}$.

3. Continuous straight-line surfaces maps for $D$ distance from the city center were computed for each city using the "Euclidean Distance" tool that calculates straight-line distance for each cell to the city centroid source. Note that the distance was clipped to be always greater than $R$, to avoid large values of gravity potential at the city centers.

4. A potential map using Eq. 2 a was computed for each city based on population, $R$, and $D$ for the city using the "Raster Calculator." 
5. A continuous density surface map of traffic volume, which is available as randomly distributed locations from MDOT, was computed using the "Kernel Density" tool. The surface map provides hotspots of high density in and around major cities and towns such as Hattiesburg, Gulfport and Laurel for which traffic volume data were available. The traffic volume density maps were then divided by road-density map to compute amplitude $A$ as in Eq. 4b. The directions of high traffic volume density $\theta_{c}$ were evaluated manually for each city, and a $V_{T r}$ potential map was calculated from Eq. 4b.

6. Potential maps computed in step 4 and step 5 were integrated for each city. Following that, maps for all the cities were integrated to obtain the first term in the right hand side of Eq. 8 .

7. Continuous maps for the distance from the roads $d_{r a}$ and railroads $d_{r o}$ were generated using "Euclidean Distance," such that each cell has the distance from the nearest road or railroad source.

8. Potential maps for $\phi_{R}$ and $\phi_{\text {RAIL }}$ were generated using distance maps created in step 7.

9. The maps in step 8 were integrated with those computed in step 6 to obtain the final CDM potential as in Eq. 8.

\subsection{Qualitative Assessment of the Wildfire Hazard Predictions}

The wildfire hazard maps predicted by CDM model are shown in Fig. 3f. The wildfire hazard maps predicted by gravity and road-density models are also presented in Fig. 3c and $d$ for comparison purposes. The road-density model predicts high wildfire hazard mostly in the southern region, which is densely populated. The predictions compare relatively well with the historic data in the southcentral region, but fails to predict the high hazard in southeastern region. The gravity model predicts high hazard in the southern region, which has abundance of both population and fuel; and towards the eastern part of domain, which is mostly characterized by high fuel quantities. When compared with the historic hazard, the model performs relatively well in the southern region, but is over predictive in the eastern region. This suggests that the model overemphasizes the effect of fuel on the wildfire predictions.

The CDM model predicts hazard mostly aligned with the interstates and major highways, and in the outskirts of the cities. The fuel distribution refines the hazard predictions, that is, hazard is higher in the high fuel region and vice versa for low fuel region (figure not shown). The predictions compare well with the historic data in the southern and central region, but over predict in the northwestern region. The overprediction in the northwestern region is primarily due to overestimation of the effect of the city potential, which needs to be further investigated. The city potential variation can be controlled by changing the power exponent of the denominator in Eq. 2a. Comparing Fig. 3a, b, c with $\mathrm{f}$, it is apparent that the CDM predictions compare better with historic winter fire hazard than annual or summer fire hazard.

\subsection{Quantitative Analysis Methods}

Quantitative comparison of the CDM with the gravity model and validation with observation data is performed using: (1) $t$ test analysis; (2) quantile analysis; (3) hazard area analysis; (4) regression analysis; and (5) evaluation of root-mean-square error (RMSE) for hazard potential prediction.

To perform t-tests, quantile, and hazard area analysis, the wildfire hazard maps predicted by Gravity and CDM models were reclassified into five zones based on quantile breaks (Cooke et al. 2007), which are named: Very Lowhazard, Low-hazard, Medium-hazard, High-hazard, and Very High-hazard zones (refer to Sadasivuni et al. 2013 for details of reclassification methodology). To perform the t-test, the entire southeastern Mississippi region was divided into 30 subregions, and the historic wildfire frequency in each subregion (and each hazard zone) was calculated.

The t-test analysis was performed to compare the wildfire mean frequency predictions by the CDM and gravity models in different hazard zones. The null hypothesis for the t-test is the mean frequency $(\mu)$ over the subregions, and is predicted similarly by both the models,

$H_{0}: \mu_{\mathrm{CDM}}-\mu_{\text {Gravity }}=0$

The null hypothesis is rejected when the predicted $p$ value $<0.05$. Otherwise, the hypothesis is accepted. An accepted hypothesis implies that both the CDM and gravity model predictions are similar for that hazard zone, whereas a rejected hypothesis implies that the model predictions do not agree.

In the quantile analysis, the number of observed wildfire events in each hazard zone for the entire domain is computed. The accuracy of the model is judged based on the wildfire frequency distribution in the hazard zones. An ideal model should predict more wildfires in the highhazard zones and less in low-hazard zones.

For the hazard area analysis, the percentage area of the validation region occupied by each hazard zone is computed. The percentage area is then compared with those figures obtained from the observational data. 
Error and linear regression analyses were performed to quantify the accuracy of the models. For this purpose, 4,000 randomly distributed points $(N)$ were generated within $2 \mathrm{~km}$ zones of the roads and cities, and historic wildfire hazard and model wildfire hazards were interpolated on these points. The points were selected within the $2 \mathrm{~km}$ zone, as most (around $80 \%$ ) of the anthropogenically-initiated wildfires lie in this region, as discussed in Sect. 2.4. The historic wildfire hazards are plotted against model predictions using a scatter plot, and a linear regression curve is fitted. An ideal prediction should show a slope of unity (1), intercept of zero (0), and $R^{2}=1$. The model predictions are judged based on deviation from the ideal prediction.

Root-mean-square error (RMSE) for the model predictions is computed as:

$$
R M S E=\sqrt{\frac{1}{N} \sum_{i-1, N}\left(\phi_{\mathrm{obs}, i}-\phi_{\mathrm{mod}, i}\right)^{2}}
$$

where, $\phi_{\text {obs }}$ and $\phi_{\text {mod }}$ are the observation potential and model potential predictions, respectively. The RMSE values are normalized using the range of hazard potential $\phi_{\max }-$ $\phi_{\min }=1$ and multiplied with 100 to express in percentage. The best predictions are those with least RMSE values.

\subsection{Quantitative Analysis of Results}

\subsubsection{T-test Analysis}

The t-test analysis in Table 1 shows that the $p<0.05$ for all the hazard zones, except the high-hazard zone for which $p=0.225$. Thus, the null hypothesis is not rejected only for the high-hazard zone. Results indicate that both the Gravity and CDM model predictions are comparable in the high-hazard zone, but are different in other hazard zones.

\subsubsection{Quantile Analysis}

The number of wildfires in each hazard zone predicted by the CDM and gravity models are shown in Fig. 11a. The gravity model predicts an increase in the frequency from Very Low- to Medium-hazard zones, but shows near uniform frequency for both of the higher hazard zones. The CDM model predicts that the wildfire frequency increases with the severity of the hazard, and most wildfires lie in High-hazard and Very High-hazard zones. However, wildfire frequency is uniform for lower hazard zones. Overall, the CDM model performs better than the gravity model for the prediction of wildfire frequency. The gravity model has some inaccuracies in the prediction of Mediumand Very High-hazard zones, similarly CDM model is overpredictive in the Very Low- and Low-hazard zones.

\subsubsection{Hazard Area Analysis}

Historic observational data in Fig. 11b show that the wildfire hazard area decreases with the severity of wildfire, except for the sharp decline in the Very Low-hazard zone. The CDM model predicts that the hazard area decreases as the severity of hazard increases. On the other hand, the gravity model predicts more or less the same range of area in every hazard zone. Almost uniform area distribution for the gravity model is expected, as it depends only on the distance from the city. Overall, CDM wildfire area predictions agree with the expected trend in the region.

\subsubsection{Regression and Error Analysis}

As shown in Fig. 12, the road-density model shows a poor correlation with the annual historic data for which the linear regression plot shows a slope of 0.78 , intercept is 0.25 , and $R^{2}=0.23$. Considering the poor prediction, seasonal regression analysis was not performed.

Gravity model predictions in Fig. 13a show a linear regression plot with slope of 0.8917 , intercept of 0.063 , and $R^{2}=0.731$ against the annual historic data, which is significantly better than road-density model predictions. The predictions are relatively poor against summer data as shown in Fig. 13a, for which the linear regression plot shows a slope of 0.597 , an intercept of 0.0792 , and an $R^{2}=0.619$. The predictions are relatively better for winter season, for which slope is 0.8145 , intercept is 0.0836 , and $R^{2}=0.7543$.

Table 1 T-test for paired two samples for gravity model and CDM mean frequency prediction in: (a) very high, (b) high, (c) medium, (d) low, and (e) very low hazard zones

\begin{tabular}{|c|c|c|c|c|c|c|}
\hline \multirow{2}{*}{$\begin{array}{l}\text { Hazard } \\
\text { Zone }\end{array}$} & \multirow[t]{2}{*}{ Model } & \multicolumn{4}{|c|}{ Variable } & \multirow[t]{2}{*}{ Comment } \\
\hline & & Mean & $\begin{array}{l}\text { Standard } \\
\text { deviation }\end{array}$ & $t$ stat & $p$ value & \\
\hline \multirow{2}{*}{$\begin{array}{l}\text { Very } \\
\text { Low }\end{array}$} & Gravity & 11.51 & 15.33 & 2.57 & 0.008 & $p<0.05$ \\
\hline & CDM & 25.76 & 27.02 & & & $\begin{array}{c}\text { Reject } \\
\text { H0 }\end{array}$ \\
\hline \multirow[t]{2}{*}{ Low } & Gravity & 27.69 & 34.18 & 2.40 & 0.011 & $p<0.05$ \\
\hline & CDM & 14.07 & 11.41 & & & $\begin{array}{c}\text { Reject } \\
\text { H0 }\end{array}$ \\
\hline \multirow[t]{2}{*}{ Medium } & Gravity & 34.38 & 39.12 & 2.68 & 0.006 & $p<0.05$ \\
\hline & $\mathrm{CDM}$ & 13.79 & 11.82 & & & $\begin{array}{c}\text { Reject } \\
\text { H0 }\end{array}$ \\
\hline \multirow[t]{2}{*}{ High } & Gravity & 29.76 & 28.91 & 0.76 & 0.225 & $p>0.05$ \\
\hline & $C D M$ & 36.10 & 43.53 & & & $\begin{array}{c}\text { Accept } \\
\text { HO }\end{array}$ \\
\hline \multirow{2}{*}{$\begin{array}{l}\text { Very } \\
\text { High }\end{array}$} & Gravity & 32.48 & 35.84 & 2.03 & 0.025 & $p<0.05$ \\
\hline & $\mathrm{CDM}$ & 45.14 & 39.39 & & & $\begin{array}{c}\text { Reject } \\
\text { H0 }\end{array}$ \\
\hline
\end{tabular}

"High" hazard zone row is in italics as this is the only zone for which null hypothesis is accepted 


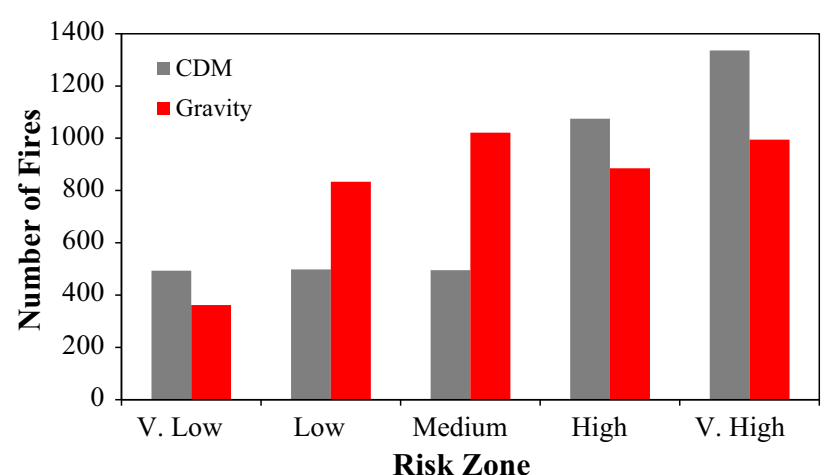

(a)

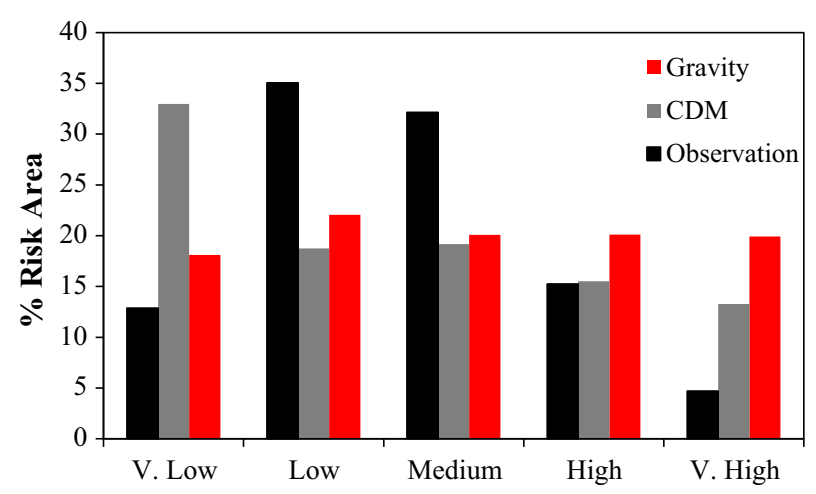

(b)

Fig. 11 a Comparison of number of fires in different hazard zones predicted by the CDM and gravity models. b Percentage of hazard area for different hazard zone predicted by CDM and gravity models

Convection-diffusion model model predictions in Fig. 14a show a linear regression plot with slope of 0.92 , intercept of 0.047 , and $R^{2}=0.8$ against the annual historic data, which is $7 \%$ better than gravity model predictions. $\mathrm{CDM}$ model predictions in Fig. $14 \mathrm{~b}$ and $\mathrm{c}$ also show a wildfire prediction trends similar to the gravity model, that is, model performance is better in winter than in summer. The best CDM prediction is against the winter historic data, which shows a linear regression plot with slope of 0.99 , intercept of 0.0212 , and $R^{2}=0.872$.

The road-density model prediction shows normalized RMSE of $18.42 \%$ against annual observational data. The gravity model predictions show normalized RMSE of 7.67, 6.99, and $14.18 \%$ when compared against annual, winter, and summer observational data, respectively. CDM predictions show normalized RMSE of 6.71, 5.08, and $9.91 \%$ when compared against annual, winter and summer, observational data, respectively.

Overall, model predictions compare better with observed fire locations in the winter season than in the summer season. This is expected as winter fires are shown to be more anthropogenically related than summer fires. CDM model performance is comparable to the gravity

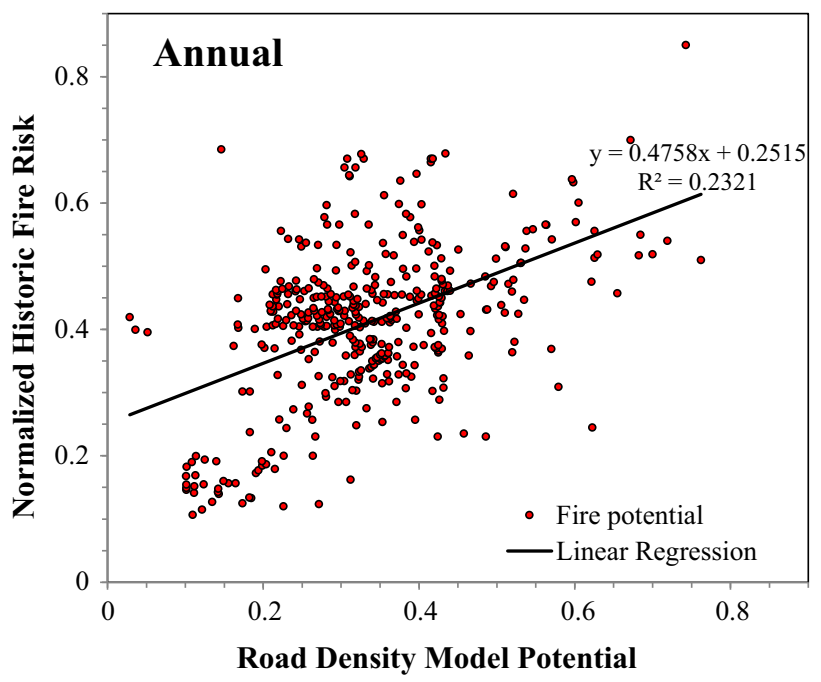

Fig. 12 Regression plot comparing the road-density model predictions with annual historical wildfire hazard in southeastern Mississippi

model in summer, slightly better for annual predictions, but outperforms the gravity model in the winter season. The normalized error for the CDM model predictions is about $5 \%$ in winter season, whereas the gravity model shows an error of $7 \%$.

\section{Conclusions and Future Work}

The study focuses on development, calibration, and validation of a spatial interaction model to predict anthropogenically-initiated accidental and incendiary wildfire ignition probabilities using a fluid dynamics analogy, in particular using convection and diffusion terms. To achieve the objective, the wildfire and transportation corridor interaction mechanism is studied using the wildfire data in the southeastern Mississippi region for an 18 year period in 1992-2009 to identify the most influential human factors for wildfire ignition. Observation data are used to calibrate the convection-diffusion model (CDM). The model is combined with a fuel layer, and the predictions are validated for wildfire hazard prediction in southeast Mississippi.

The analysis of observation wildfire data shows that over $65 \%$ of the wildfires in the region are due to arson, and most burn areas average 10-50 acres. Wildfire activity in the region correlates very well with the wildfire drought index, validating the expected strong correlation of wildfires with climatic factors. About two-third of the wildfires occur in winter season and show peaks in the late and early winter. In addition, winter wildfires are clustered near the populated regions and roads connecting them, whereas summers fires are more or less evenly distributed. The high 


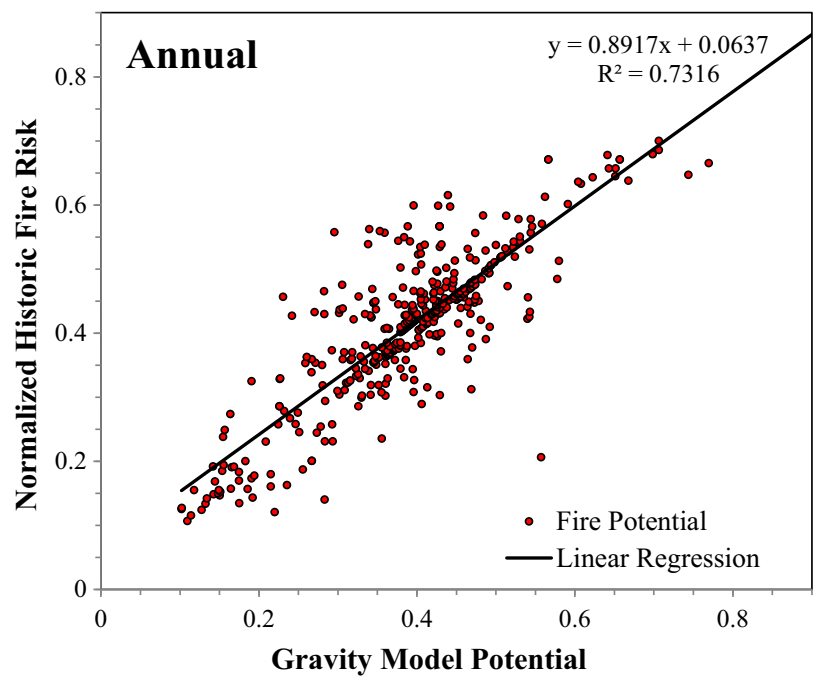

(a)

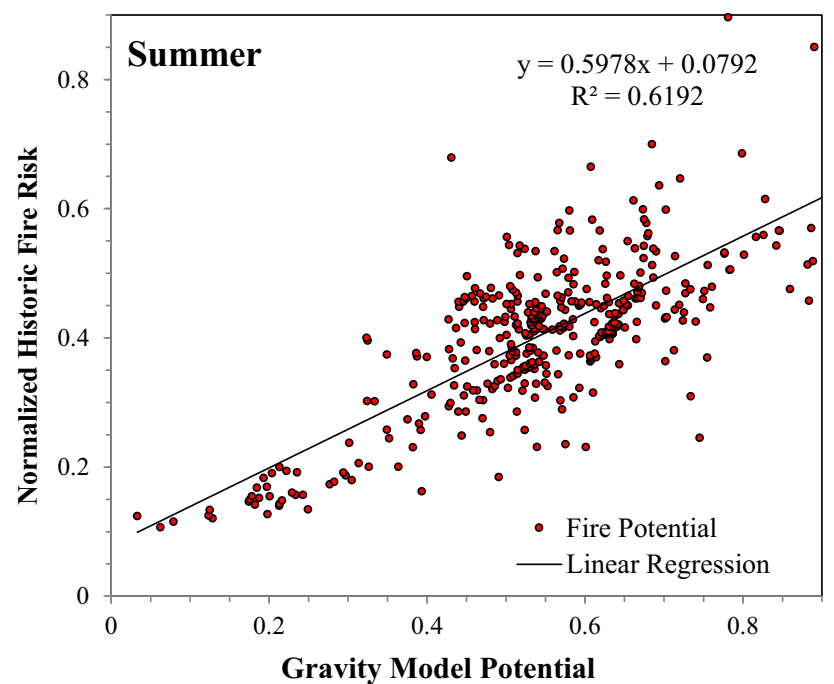

(b)

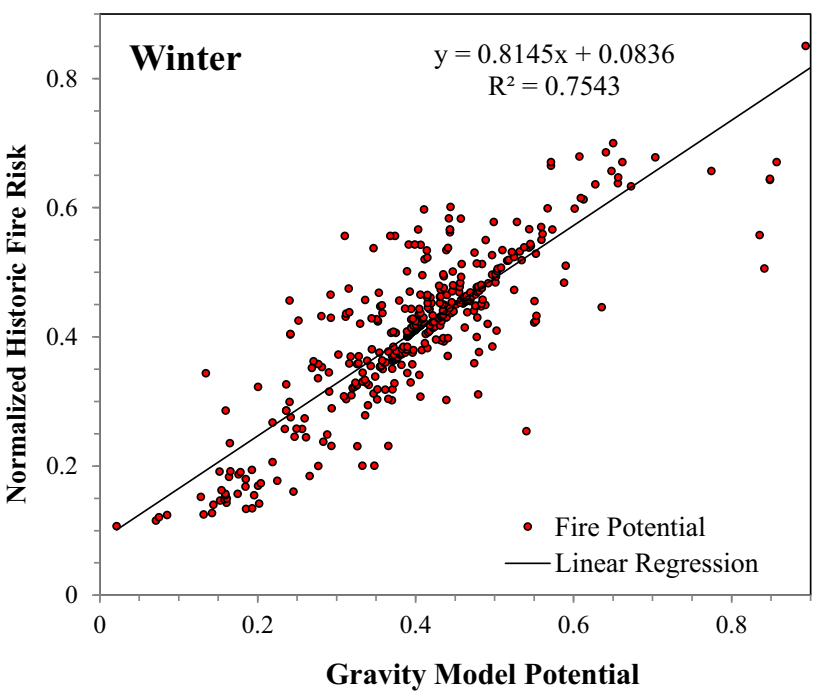

(c)

Fig. 13 Regression plot comparing the gravity model predictions with a annual, b summer, and $\mathbf{c}$ winter season historical wildfire hazard in southeastern Mississippi region

number of wildfires in the early and late winter season, when the natural conditions are less prone to wildfire and the human activity pattern is expected to be higher, suggests that winter fires have a stronger correlation with anthropogenic factors than do summer fires. About $80 \%$ of the wildfires occur within a $2 \mathrm{~km}$ zone along designated highways, and the frequency decays exponentially as the distance from the road increases. In and around cities, wildfires mostly occur in the suburban areas, and are aligned along the higher traffic volume roads.

A convection-diffusion model for wildfire ignition potential is developed by grouping the anthropogenic factors as "global" and "local" variables, where city or population interactions are global variables and the transportation corridors are local variables. The city potential is modeled as a gravity term with dampening inside the city, the variation of potential due to the roads and railroads are modeled as diffusive fluxes, and the potential along the high traffic volume direction is modeled as convective fluxes. An analytic form of the model is developed assuming that the transportation corridor and city potential are uncorrelated; and the traffic volume and population influences the city potential along the circumferential and radial directions, respectively. The unknown model coefficients for convection parameter and diffusivity are calibrated from the observational data. The model formulation is first validated for simplified representations of the Hattiesburg region, wherein the model terms performed as expected. 


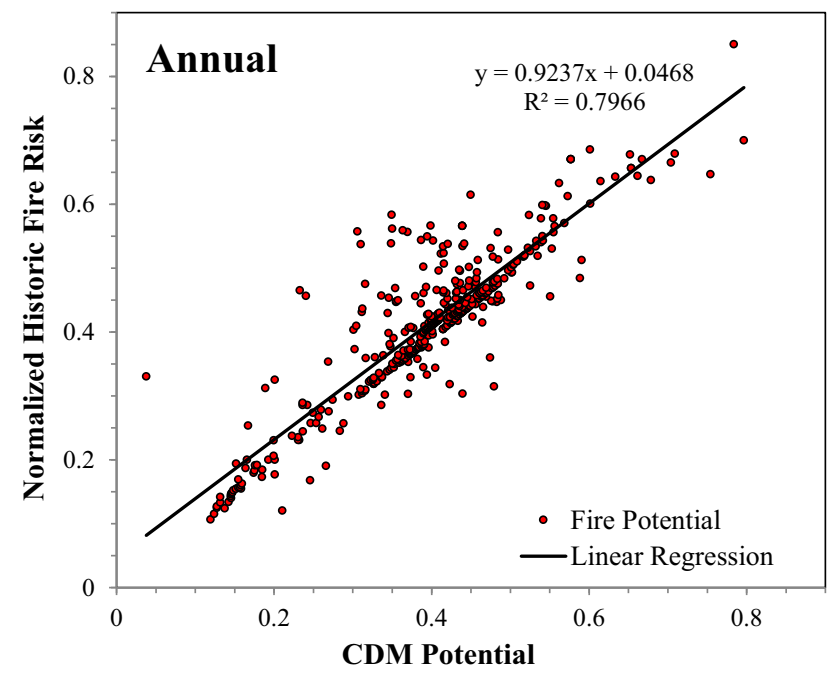

(a)

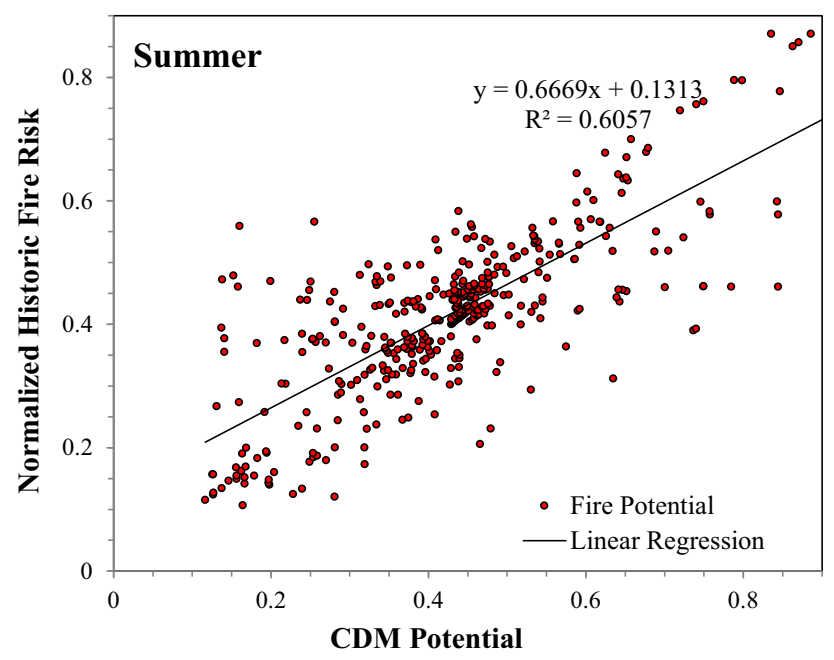

(b)

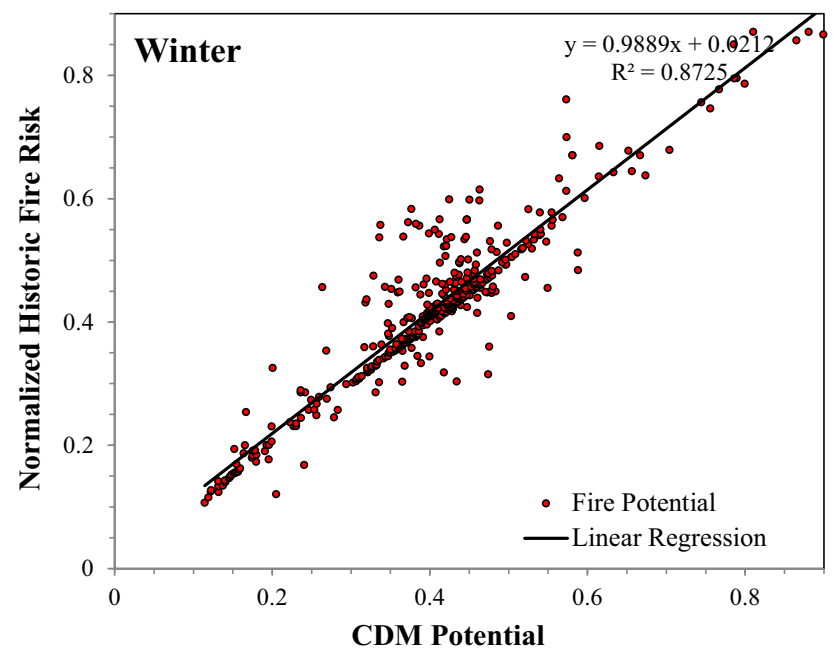

(c)

Fig. 14 Regression plot comparing the CDM model predictions with a annual, b summer, and $\mathbf{c}$ winter season historical wildfire hazard in southeastern Mississippi

The CDM model was implemented in ArcGIS and combined with a fuel layer to predict wildfire hazard potential in southeast Mississippi. The model prediction was compared with gravity model predictions and historic observation data. Both the CDM and gravity model agree with the prediction of a high-hazard zone, but they disagree in their predictions of low-, medium- and very high-hazard zones. Both models show better agreement with the historic observation data in winter season than in summer season; that is, average $R^{2}=0.61$ in summer and average $R^{2}=0.81$ in winter. The CDM model performs better than the gravity model in the prediction of wildfire frequency, hazard area, and wildfire hazard distribution. The CDM predictions shows good correlation with winter wildfire data for which $R^{2}=0.87$, whereas the gravity model shows modest correlation with $R^{2}=0.75$. The normalized error for the CDM model predictions is about $5 \%$ in winter season, whereas the gravity model shows an error of $7 \%$. The improved prediction by CDM model over the gravity model, especially in the very high-hazard zone, is due to its ability to account for anthropogenic hazards along the roads.

Overall, the study validates the premise that a convection-diffusion based wildfire ignition model captures the anthropogenically-initiated wildfire ignition behavior better than the previously developed gravity model. The proposed model is more costly than the gravity model as it requires evaluation of distance from intermodal 
transportation corridor, transportation corridor density, and traffic volume maps. Nonetheless, the model is developed in a modular fashion, such that either of the terms can be neglected if required.

The wildfire ignition model developed in this study can provide a static ignition layer, which can be combined with dynamic meteorological conditions and a fuel layer within the GIS framework, to refine the locations and seasonal variations of the wildfire hazards. Such a model can help better plan wildfire mitigation (fuel reduction) and response. Such a GIS tool can also be used for land use planning and development, and to predict initiation of wildfires, which can be combined with wind flow dynamics in the atmospheric boundary layer to predict fire behavior, in particular the advancement of a fire front. Future research efforts will focus on: (1) identification of an appropriate fusion criteria for ignition, meteorological conditions, and fuel layers; (2) development of accurate interpolation techniques as the different layers may have different data resolution; (3) improved derivation of the fuel layer using canopy height and leaf-area index following Ashworth et al. (2010); and (4) increased specificity when calculating the city potential damping effect that is currently modeled as a circular function. The dampening effect can be viewed as an amoebic-type polygon that is sensitive to changes in population density across cityscapes and can serve to further inform the global and local parameters estimation.

Open Access This article is distributed under the terms of the Creative Commons Attribution License which permits any use, distribution, and reproduction in any medium, provided the original author(s) and the source are credited.

\section{References}

Ashworth, A., D. Evans, W. Cooke, A. Londo, C. Collins, and A. Neuenschwander. 2010. Predicting southeastern forest canopy heights and fire fuel models using GLAS data. Photogrammetric Engineering and Remote Sensing 76(8): 915-922.

Ayeni, M.A.O. 1979. Concepts and techniques in urban analysis. London: Croom Helm Books.

Brewer, J.S., and C.H. Rogers. 2006. Relationships between prescribed burning and wildfire occurrence and intensity in pinehardwood forests in north Mississippi, USA. International Journal of Wildland Fire 15: 203-211.

Burgan, R.E., R.W. Klaver, and J.M. Klaver. 1998. Fuel models and fire potential from satellite and surface observations. International Journal of Wildland Fire 8(3): 159-170.

Cardille, J.A., S.J. Ventura, and M.G. Turner. 2001. Environmental and social factors influencing wildfires in the upper Midwest. United States. Ecological Applications 11(1): 111-127.

Catry, F.X., F.C. Rego, F.L. Bação, and F. Moreira. 2009. Modeling and mapping wildfire ignition risk in Portugal. International Journal of Wildland Fire 18(8): 921-931.

Chan, Y. 2011. Location theory and decision analysis, 2nd ed. Berlin: Springer.
Cooke, W.H., K. Grala, D.L. Evans, and C. Collins. 2007. Assessment of pre- and post-Katrina fuel conditions as a component of fire potential modeling for southern Mississippi. Journal of Forestry 105(8): 389-397.

Dickson, B.G., J.W. Prather, Y. Xu, H.M. Hampton, E.N. Aumack, and T.D. Sisk. 2006. Mapping the probability of large fire occurrence in northern Arizona, USA. Landscape Ecology 21(5): $747-761$.

Dutta, S. 2010. Spatio-temporal characteristics of Mississippi wildfires. Thesis, Mississippi State University, Starkville, MS.

EC (European Commission). 2012. The European Forest Fire Information System: New fire causes classification scheme adopted for the European Fire Database. European Commission-Joint Research Centre Report, Version 1, April 2012.

Eccleston, C.H. 2011. Environmental impact assessment: A guide to best professional practices. Boca Raton, Fl: CRC Press.

Faghri, A.J., A.J. Lang, and H.E. Henck. 2001. An AL-based hybrid system for locating of park-and-ride facilities. Transportation Research Board, 80th Annual Meeting, Washington, DC.

Faivre, N., Y. Jin, M.L. Goulden, and J.T. Randerson. 2014. Controls on the spatial pattern of wildfire ignitions in Southern California. International Journal of Wildland Fire 23(6): 799-811.

Fotheringham, A.S., and M.E. O'Kelly. 1989. Spatial interaction models: Formulations and applications. Dordrecht: Kluwer Academic Publishers.

Fowler, C., and E. Konopik. 2007. The history of fire in the southern United States. Human Ecology Review 14(2): 165-176.

Gilreath, J.M. 2006. Validation of variables for the creation of a descriptive fire potential model for the Southeastern Fire District of Mississippi. Thesis, Mississippi State University, Starkville, MS.

Grala, K., and W.H. Cooke. 2010. Spatial and temporal characteristics of wildfires in Mississippi, USA. International Journal of Wildland Fire 19(1): 14-28.

Haight, R.G., D.T. Cleland, R.B. Hammer, V.C. Radeloff, and T.S. Rupp. 2004. Assessing fire risk in the wildland-urban interface. Journal of Forestry 102(7): 41-48.

Heyerdahl, E.K., L.B. Brubaker, and J.K. Agee. 2001. Spatial controls of historical fire regimes: A multiscale example from the interior west, USA. Ecology 82(3): 660-678.

Holmes, E., M. Lewis, J. Banks, and R. Veit. 1994. Partial differential equations in ecology: Spatial interactions and population dynamics. Ecology 75(1): 17-29.

Huff, D.L. 1963. A probabilistic analysis of shopping center trade areas. Land Economics 39(1): 81-90.

Kathrin, F. 2011. Central places: The theories of von Thünen. In Foundations of location analysis, International Series in Operations Research \& Management Science, 155, ed. H.A. Eiselt, H.S. Frederick, P.C. Camille, and V. Marianov, 471-505. New York: Springer.

Kraskey, R. 1985. Incendiary wildfires: Minnesota gets tough on arsonists. Fire Management Notes 46(1): 16-18.

Kuhlken, R. 1999. Setting the woods on fire: Rural incendiarism as protest. Geographical Review 89(3): 343-363.

McCormack, E. 1999. Using a GIS to enhance the value of travel diaries. Institute of Transportation Engineers Journal 69(1): $38-43$.

Miller, C. 2003. Wildland fire use: A wilderness perspective on fuel management. Fire, fuel treatments, and ecological restoration. In USDA Forest Service, Rocky Mountain Research Service Proceedings, ed. P.N. Omi and L.A. Joyce, 379-385. Fort Collins, CO.

Narayanaraj, G., and M.C. Wimberly. 2012. Influences of forest roads on the spatial pattern of human- and lightning-caused wildfire ignitions. Applied Geography 32(2): 878-888. 
Oldham, K.T.S. 2008. The doctrine of description: Gustav Kirchhoff, classical physics, and the "purpose of all science" in 19thcentury Germany. Ph.D. Thesis, University of California, Berkeley.

Openshaw, S. 1998. Neural network, genetic, and fuzzy logic models of spatial interaction. Environment \& Planning A 30(10): $1857-1872$.

ORNL (Oak Ridge National Laboratory). 2011. Freight management and operations. Federal Highway Administration, http://faf.ornl. gov/fafweb/Data/Freight_Traffic_Analysis/chap5.htm. Accessed 6 Nov 2014

Parsons, D.J. 2000. The challenge of restoring natural fire to wilderness. In Wilderness science in a time of change conference: Wilderness ecosystems, threats, and management. Proceedings RMRS-P-15, Vol 15, U.S. Department of Agriculture Forest Service, Missoula, Montana, ed. D.N. Cole, S.F. McCool, W.T. Borrie, and J. O'Laughlin, 276-282.

Petrakis, M., B. Psiloglou, M. Lianou, I. Keramitsoglou, and C. Cartalis. 2005. Evaluation of forest fire risk and fire extinction difficulty at the mountainous park of Vikos-Aoos, Northern Greece: Use of remote sensing and GIS techniques. International Journal of Risk Assessment and Management 5(1): 50-65.

Pew, K.L., and C.P.S. Larsen. 2001. GIS analysis of spatial and temporal patterns of humancaused wildfires in the temperate rain forest of Vancouver Island, Canada. Forest Ecology and Management 140: 1-18.

Porojan, A. 2001. Trade flows and spatial effects: The gravity model revisited. Open Economies Review 12(3): 265-280.

Pyne, S.J., P.L. Andrews, and R.D. Laven. 1996. Introduction to wildland fire. New York: Wiley.

Rietveld, P., and M.P. Nijkamp. 2002. Spatial interaction models. In Handbook of transportation science, ed. R. Hall, 279-320. Norwell: Kluwer Academic Publishers.

Romero-Calcerrada, R., C.J. Novillo, J.D.A. Millington, and I. Gomez-Jimenez. 2008. GIS analysis of spatial patterns of human-caused wildfire ignition risk in the SW of Madrid (Central Spain). Landscape Ecology 23(3): 341-354.

Sadasivuni, R. 2013. Urban fringe, transportation corridor convection-diffusion model for anthropogenically-initiated wildfire ignition prediction. Ph.D. dissertation, Mississippi State University.

Sadasivuni, R.R., O’Hara, C.G., Nobrega, R., Dumas, J. (2009). A transportation corridor case study for multi-criteria decision analysis. In Proceedings American Society of Photogrammetry and Remote Sensing Conference, Baltimore, MD.

Sadasivuni, R., W.H. Cooke, and S. Bhushan. 2013. Wildfire risk prediction in southeastern Mississippi using population interaction. Ecological Modeling 251: 297-306.

Shields, R. 1997. Flow as a new paradigm. Space and Culture 1(1): $1-7$.

Stephens, S.L. 2005. Forest fire causes and extent on United States Forest Service lands. International Journal of Wildland Fire 14(3): 213-222.

Stillwell, J., O.W. Duke, and A. Dennett. 2010. Technologies for migration and commuting analysis: Spatial interaction data applications. Hershey, PA: Business Science Reference (IGI Global).

Stouffer, S.A. 1940. Intervening opportunities: A theory relating mobility and distance. American Sociological Review 5(6): $845-867$.

Syphard, A., V. Radeloff, J. Keeley, T. Hawbaker, M. Clayton, S. Stewart, and R. Hammer. 2007. Human influence on California fire regimes. Ecological Applications 17(5): 1388-1402.

Tobler, W.R. 1976. Spatial interaction patterns. Journal of Environmental Systems 6(4): 271-301.

USDA (U.S. Department of Agriculture) and USDI (U.S. Department of the Interior). 1998. Wildland fire and prescribed fire management policy: Implementation procedures reference guide. Boise: National Interagency Fire Center.

Vasconcelos, M.J.P., S. Silva, M. Tome, M. Alvim, and J.C. Pereira. 2001. Spatial prediction of fire ignition probabilities: Comparing logistic regression and neural networks. Photogrammetric Engineering and Remote Sensing 67(1): 73-81.

Wilson, J.P., and P.A. Burrough. 1999. GIS, dynamic modeling, geostatistics, and fuzzy classification: New sneakers for a new geography? Annals of the Association of American Geographers 89(4): 736-746.

Yang, J., H.S. He, S.R. Shifley, and E.J. Gustafson. 2007. Spatial patterns of modern period human-caused fire occurrence in the Missouri Ozark Highlands. Forest Science 53(1): 1-15.

Zhai, Y.S., I.A. Munn, and D.L. Evans. 2003. Modeling forest fire probabilities in the South Central United States using FIA data. Southern Journal of Applied Forestry 27(1): 11-17. 